\title{
Article \\ Numerical Study of Thermophoresis on Mass Transfer from Natural Convection Flow over a Vertical Porous Medium with Variable Wall Heat Fluxes
}

\author{
Jian-Sheng Huang
}

check for updates

Citation: Huang, J.-S. Numerical Study of Thermophoresis on Mass Transfer from Natural Convection Flow over a Vertical Porous Medium with Variable Wall Heat Fluxes. Appl. Sci. 2021, 11, 10418. https://doi.org/ 10.3390/app112110418

Academic Editor: Francesca Scargiali

Received: 4 October 2021

Accepted: 3 November 2021

Published: 5 November 2021

Publisher's Note: MDPI stays neutral with regard to jurisdictional claims in published maps and institutional affiliations.

Copyright: (C) 2021 by the author. Licensee MDPI, Basel, Switzerland. This article is an open access article distributed under the terms and conditions of the Creative Commons Attribution (CC BY) license (https:/ / creativecommons.org/licenses/by/ $4.0 /)$.
Department of Mechanical Engineering, Chung Yuan Christian University, Chung Li 32023, Taiwan; jshuang@cycu.edu.tw

\begin{abstract}
This study investigates heat and mass transfer under natural convection flow along a vertical permeable surface with variable wall heat fluxes through a porous medium. The nonDarcian model is employed for the medium. The effects of suction/blowing, inertia, buoyancy ratio, exponent of heat flux, position parameter, Schmidt number, and thermophoresis are considered. The governing equations of continuity, momentum, energy, and concentration are solved by adopting similarity transformation and Runge-Kutta integration with a shooting technique. Results of interest, such as velocity, temperature, and concentration profiles related to local Nusselt and Sherwood numbers, are obtained for the selected buoyancy ratio at different magnitudes of the thermophoretic effect. The numerical solutions help us to realize the gas diffusion phenomena and control the transport technology.
\end{abstract}

Keywords: thermophoresis; non-Darcy; power-law heat flux; porous medium; natural convection

\section{Introduction}

Thermophoresis is a physical phenomenon of mass transfer, subjected to a temperature gradient, which moves from higher to lower temperature zones of the gas fluid. It plays a significant role in laminar boundary layer flow and is well researched through theoretical and experimental procedures. Additionally, the thermophoretic driving force occurring in convection flow through a porous medium has attracted significant attention because of widely practical application cases, such as in aerosol particles sampling, vehicle air cleaning, filtration process, scale formation inside tube systems of heat exchangers, particle deposition on gas turbine blades, the semiconductor manufacturing process, and wasted gas exhaust systems from combustion. Goldsmith and May [1] first studied coupled diffusiophoresis and thermophoresis in a simple one-dimensional water vapor system for the measurement of thermophoretic velocity. Another earlier study on the role of thermophoresis in the laminar flow of viscous and incompressible fluids over a horizontal plate, with analysis on cold and hot wall surface conditions, was proposed by Goren [2]. He adopted the classical problem of flow over a flat plate to calculate the deposition rates and stated that significant changes in surface depositions could be obtained by increasing the surface and free stream temperature difference. Some studies [3-6] have also been presented to discuss the coupled diffusion and thermophoresis interactive effect phenomena based on fundamental research. Talbot et al. [7] established the numerical solution for the velocity and temperature fields in the laminar boundary layer adjacent to a heated plate. They proposed several available theoretical expressions for the thermophoretic force. Chamkha and Pop [8] investigated heat and mass transfer through a steady laminar boundary layer flow of a Newtonian, viscous fluid over a vertical flat plate embedded in a porous medium in the presence of the thermophoresis particle deposition effect and obtained the wall concentration profiles. Seddeek [9] investigated the mixed convection flow, heat, and mass transfer about an isothermal vertical flat plate embedded in a fluid-saturated porous 
medium with the effects of thermophoresis and viscous dissipation in aiding and opposing flows and obtained the results in terms of the local Nusselt and Sherwood number. Subsequently, he proposed a mathematical model to analyze the local similarity boundary layer to investigate the effects of thermophoresis and variable thermal conductivity on heat and mass transfer over an accelerating surface with a heat source in the presence of suction and blowing [10].

Darcy's law was applied to fluid flow through a porous medium to prove that the pressure drop produced by the frictional drag is proportional to the velocity of low-speed flow. For high flow velocity with Reynolds numbers based on a mean pore diameter greater than 1, Darcy's law should be corrected to incorporate non-Darcian effects, including inertia and boundary effects. Bejan and Anderson [11] described the effects of stable thermal stratification for free convection of two conjugate boundary layers on both sides of an impermeable vertical partition embedded in a porous medium. Afterward, Bejan and Khair [12] proposed a fundamental study of natural convection heat and mass transfer near a vertical surface embedded in a fluid-saturated porous medium. They used scale analysis to show that the physical phenomenon of natural convection heat and mass transfer was a function of the buoyancy ratios and Lewis numbers. Nakayama and Koyama [13,14] obtained the similarity and integral solutions for the problem of the free convection boundary layer along a vertical plate immersed in a thermally stratified, fluid-saturated porous medium with variable wall temperature.

Studies on mass transfer due to thermophoresis in laminar convective flow have also been presented. Epstein et al. [15] conducted a thermophoretic analysis of small particles in a free convection boundary layer flow adjacent to a cold vertical plate. Jayaraj et al. [16,17] dealt with thermophoresis in natural convection with variable properties for a laminar flow over a cold flat plate. Zueco et al. [18] presented a mathematical model for the laminar heat and mass transfer of an electrically conducting, heat-generating/absorbing fluid past a perforated horizontal surface in the presence of Joule heating and thermophoresis. Meanwhile, studies on the thermophoretic effect for flow through porous media have been gradually developed. Chamkha et al. [19] proposed a study on the steady free convection over an isothermal vertical circular cylinder embedded in a fluid-saturated porous medium. Similar studies on convective flows in porous media were surveyed in the books by Nield and Bejan [20] and Ingham and Pop [21,22]. Although several studies have been discussing the thermophoretic effect on convection flow, or fluid flow over porous media in the literature [23-30], there is still a lack of published papers probing natural convective flow through a porous medium with heat and mass transfer rates for a low Schmidt number under variable wall heat fluxes. Commonly, the air pollution substance comes from aerosol particles and toxic gaseous molecules with low Schmidt numbers, such as hydrocarbons or sulfur dioxide $\left(\mathrm{SO}_{2}\right)$. In this study, we investigate the mechanism of heat and mass transfer over a vertical permeable surface with variable heat fluxes through a porous medium by the coupled effects of diffusion, convection, suction/blowing, non-Darcy, and thermophoresis. The low Schmidt number of gases is examined. The physical impact of the proposed analysis would be helpful for air pollution control engineering, such as gas diffusion and filtration processes in a porous medium.

\section{Mathematical Formulation}

Figure 1 shows the physical model for a two-dimensional steady natural convection flow over a vertical permeable surface with a power-law wall heat flux $q_{w}(x)$ and a constant concentration $C_{w}$. The ambient temperature and concentration are $T_{\infty}$ and $C_{\infty}$, respectively. The coordinates are $x$, measured along the surface from its leading edge, and the $y$ normal to the system. The following assumptions are made for the system:

1. The boundary layer approximations can be applied to the flow.

2. The convective fluid and porous structure are everywhere in local thermodynamic equilibrium. 
3. There is no phase change of the fluid in the medium, and thermal dispersion effects are neglected.

4. The Boussinesq approximation is employed; that is,

$$
\rho=\rho_{\infty}\left[1-\beta_{T}\left(T-T_{\infty}\right)-\beta_{C}\left(C-C_{\infty}\right)\right]
$$

where the subscript " $\infty$ " refers to the ambient condition. The volumetric expansion coefficients for thermal and concentration are

$$
\beta_{T}=-\frac{1}{\rho}\left(\frac{\partial \rho}{\partial T}\right)_{P, C}, \beta_{C}=-\frac{1}{\rho}\left(\frac{\partial \rho}{\partial C}\right)_{T, P}
$$

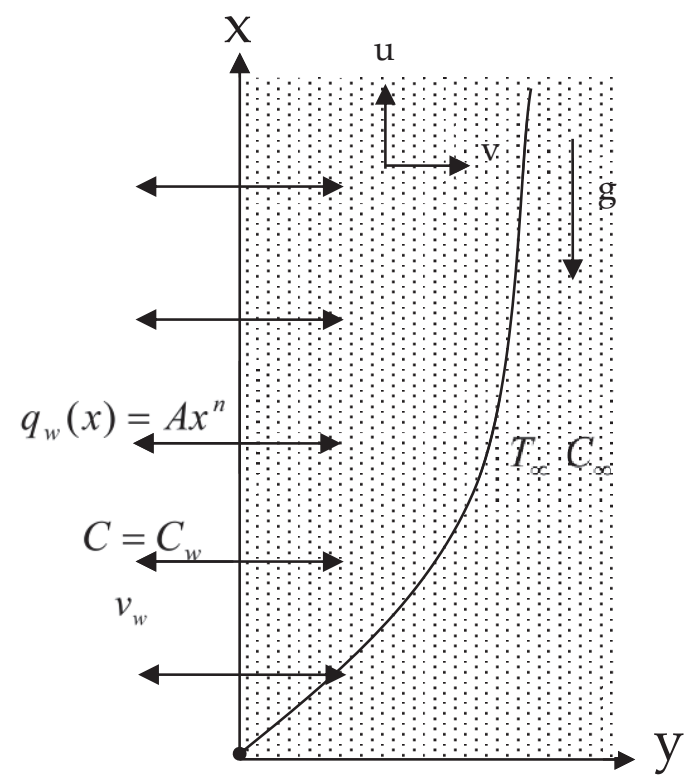

Figure 1. Schematic of natural convection flow over a vertical permeable surface physical model and coordinate system.

The value of $C_{\infty}$ is set to zero in the problem as the concentration of species far from the wall; $C_{\infty}$ is sufficiently small [31]. The thermophysical properties are maintained constant. The conservation equations for fluid flow through an isotropic and homogeneous saturated porous medium can be written as follows:

1. Continuity equation

$$
\frac{\partial u}{\partial x}+\frac{\partial v}{\partial y}=0
$$

2. Momentum equation

$$
\frac{\rho}{\varepsilon^{2}}\left(u \frac{\partial u}{\partial x}+v \frac{\partial u}{\partial y}\right)=\rho_{\infty} g\left[\beta_{T}\left(T-T_{\infty}\right)+\beta_{C}\left(C-C_{\infty}\right)\right]+\frac{\mu}{\varepsilon} \frac{\partial^{2} u}{\partial y^{2}}-\frac{\mu}{K} u-\rho C_{i} u^{2}
$$

3. Energy equation

$$
u \frac{\partial T}{\partial x}+v \frac{\partial T}{\partial y}=\alpha_{e} \frac{\partial^{2} T}{\partial y^{2}}
$$

4. Concentration equation

$$
u \frac{\partial C}{\partial x}+v \frac{\partial C}{\partial y}+\frac{\partial}{\partial y}\left(C V_{T}\right)=D_{e} \frac{\partial^{2} C}{\partial y^{2}}
$$


The boundary conditions for Equations (3) to (6) are

$$
\begin{gathered}
x=0, \quad y>0, \quad T=T_{\infty} \quad C=C_{\infty} \quad u=0 \\
x>0, \quad y=0, \quad q_{w}(x)=A x^{n} \quad C=C_{w} \quad u=0 \quad v=v_{w} \\
y \rightarrow \infty, \quad T=T_{\infty} \quad C=C_{\infty} \quad u=0
\end{gathered}
$$

where $u$ and $v$ are flow velocities in the $x$ and $y$ direction, respectively. $T$ is the temperature, $\mu$ is the dynamic viscosity, and $k$ is the thermal conductivity. $A$ is the constant strength of wall heat source, and $n$ is a power-law exponent of heat flux. $\rho$ is the fluid density. $\varepsilon$ and $K$ are the porosity and permeability of the porous medium, respectively. $v_{w}$ represents the suction/blowing velocity of the permeable surface, and $g$ is the acceleration due to gravity. $C_{i}$ is the transport property related to the inertia effect. $\alpha_{e}$ and $D_{e}$ are the effective thermal and mass diffusivity of the porous medium, respectively. $V_{T}$ is the thermophoretic velocity given by Talbot et al. [7], as follows:

$$
V_{T}=-\kappa \frac{v}{T} \frac{\partial T}{\partial y}
$$

where $\kappa$ is the thermophoretic coefficient defined using [32]

$$
\kappa=\frac{2 C_{s}\left(\lambda_{g} / \lambda_{p}+C_{t} K n\right) C_{c}}{\left(1+3 C_{m} K n\right)\left(1+2 \lambda_{g} / \lambda_{p}+2 C_{t} K n\right)}
$$

where $C_{s}, C_{t}$, and $C_{m}$ are constants. $\lambda_{g}$ and $\lambda_{p}$ are the thermal conductivities of the fluid and diffused particles, respectively. $C_{c}=1+K n\left(C_{1}+C_{2} e^{-C_{3} / K n}\right)$ is the Cunningham correction factor, and $K n$ is the Knudsen number. The values of permeability $K$ and inertia coefficient $C_{i}$ for the non-Darcian effects on solid-fluid combinations are used by employing Ergun's model [33,34]:

$$
\begin{aligned}
K & =\frac{d^{2} \varepsilon^{3}}{150(1-\varepsilon)^{2}} \\
C_{i} & =\frac{1.75(1-\varepsilon)}{\varepsilon^{3} d}
\end{aligned}
$$

The governing equations can be transformed using the dimensionless stream function, $f(\xi, \eta)$, dimensionless temperature, $\theta(\xi, \eta)$, and dimensionless concentration, $\phi(\xi, \eta)$, with the following parameters:

$$
\begin{gathered}
\eta(x, y)=\frac{y}{x} R a_{x}{ }^{1 / 5}, \xi(x)=\frac{x^{2}}{K} R a_{x}{ }^{-2 / 5}, f(\xi, \eta)=\frac{\psi(x, y)}{\alpha_{e} R a_{x}{ }^{1 / 5}} \\
\theta(\xi, \eta)=\frac{T-T_{\infty}}{T^{*}} R a_{x}{ }^{1 / 5}, \phi=\frac{C-C_{\infty}}{C_{w}-C_{\infty}}=\frac{C-C_{\infty}}{\Delta C}, N t=\frac{T_{\infty}}{T^{*}} R a_{x}{ }^{1 / 5}, T^{*}=\frac{x q_{w}(x)}{k}
\end{gathered}
$$

where $\psi(x, y)$ is the stream function satisfying Equation (3) with $u=\partial \psi / \partial y$ and $v=$ $-\partial \psi / \partial x$.

Substituting Equation (12) into Equations (4)-(7), we obtain the following system:

$$
\begin{aligned}
& \frac{1}{\varepsilon} f^{\prime \prime \prime}+\theta+N \phi-\frac{1}{5 \varepsilon^{2} \operatorname{Pr}}\left[(2 n+3)\left(f^{\prime}\right)^{2}-(n+4) f f^{\prime \prime}\right]-\xi f^{\prime}-\xi^{5 / 4} \frac{\gamma^{1 / 2}}{\operatorname{Pr}}\left(f^{\prime}\right)^{2}=\frac{2(1-n)}{5 \varepsilon^{2} \operatorname{Pr}} \xi\left(f^{\prime} \frac{\partial f^{\prime}}{\partial \xi}-f^{\prime \prime} \frac{\partial f}{\partial \xi}\right) \\
& \theta^{\prime \prime}+\frac{n+4}{5} f \theta^{\prime}+\frac{-1-4 n}{5} f^{\prime} \theta=\frac{2(1-n)}{5} \xi\left(f^{\prime} \frac{\partial \theta}{\partial \xi}-\theta^{\prime} \frac{\partial f}{\partial \xi}\right) \\
& \frac{1}{S c} \phi^{\prime \prime}+\left(\frac{n+4}{5 \operatorname{Pr}} f+\kappa \frac{1}{N t+\theta} \theta^{\prime}\right) \phi^{\prime}+\left[\kappa \frac{1}{N t+\theta} \theta^{\prime \prime}-\kappa\left(\frac{1}{N t+\theta}\right)^{2}\left(\theta^{\prime}\right)^{2}\right] \phi=\frac{2(1-n)}{5 \operatorname{Pr}} \xi\left(f^{\prime} \frac{\partial \phi}{\partial \xi}-\phi^{\prime} \frac{\partial f}{\partial \xi}\right) \\
& \eta=0, \quad f(\xi, 0)=f_{w} \quad f^{\prime}(\xi, 0)=0 \quad \theta^{\prime}(\xi, 0)=-1 \quad \phi(\xi, 0)=1
\end{aligned}
$$




$$
\eta \rightarrow \infty, \quad f^{\prime}(\xi, \infty)=0 \quad \theta(\xi, \infty)=0 \quad \phi(\xi, \infty)=0
$$

where the primes denotes partial differentiation with respect to $\eta, R a_{x}=\left(g \beta_{T} T^{*} x^{3}\right) / \alpha_{e} v$ is the Rayleigh number, and $T^{*}$ is the characteristic temperature. $\operatorname{Pr}=v / \alpha_{e}$ is the Prandtl number (0.7 used for air). $S c=v / D_{e}$ is the Schmidt number $(0.1$ to 2.5 is selected for gas species diffusing into the air [35]). $N=\left(\beta_{C} \Delta C / \beta_{T} T^{*}\right) R a_{x}{ }^{1 / 5}$ is the buoyancy ratio defined as the driving force intensity of the concentration source to the wall heat flux under natural convection. The parameter $N>0$ coincides with the aiding buoyancy, whereas $N<0$ represents the opposing buoyancy. Additionally, $\gamma=\left(K^{5 / 2} C_{i}^{2} g \beta_{T} T^{*}\right) / \alpha_{e} v$ is the dimensionless inertia parameter, and $N t$ is the thermophoretic parameter from the driving force by the temperature gradient acting on the diffused species. $f_{w}$ is the dimensionless wall suction/blowing velocity; $f_{w}<0$ for surface blowing, and $f_{w}>0$ for surface suction.

The important physical quantities of our interests are the local Nusselt number, $N u_{x}$, for heat transfer, and the Sherwood number, $S h_{x}$, for mass transfer, and mass transfer conductance, $g_{m x}$. The local Nusselt and Sherwood numbers are obtained using the methods in [35], as follows:

$$
N u_{x}=\frac{q_{w} x}{\left(T_{w}-T_{\infty}\right) k}=\left[\frac{1}{\theta(\xi, 0)}\right] R a_{x}^{1 / 5}, S h_{x}=\frac{J_{w} x}{\left(C_{w}-C_{\infty}\right) D_{e}}=-\phi^{\prime}(\xi, 0) R a_{x}{ }^{1 / 5}
$$

where $J_{w}$ is the wall mass flux defined by

$$
J_{w}=-\left.D_{e} \frac{\partial C}{\partial y}\right|_{y=0}=g_{m x}\left(C_{w}-C_{\infty}\right)
$$

The ratio of mass fluxes with and without the suction/blowing effect is given by

$$
\frac{J_{w}}{J_{w}{ }^{*}}=\frac{g_{m x}}{g^{*} m x}=\frac{\phi^{\prime}(\xi, 0)}{\left.\phi^{\prime}(\xi, 0)\right|_{f_{w}=0}}
$$

where $g_{m x}$ and $g^{*} m x$ is the mass transfer conductance and zero-mass transfer limit conductance, respectively.

\section{Results and Discussions}

In this study, we adopt the local non-similarity method [36-40] to solve Equations (13)-(15). Considering equating up to the second level of truncation gives almost-accurate results compared with the solutions from other methods, such as the finite-difference method. To do this, we introduce the following new function $G=\partial f / \partial \xi, H=\partial \theta / \partial \xi$, and $I=\partial \phi / \partial \xi$ into Equations (13)-(15), to obtain

$$
\begin{gathered}
\frac{1}{\varepsilon} f^{\prime \prime \prime}+\theta+N \phi-\frac{1}{5 \varepsilon^{2} \operatorname{Pr}}\left[(2 n+3)\left(f^{\prime}\right)^{2}-(n+4) f f^{\prime \prime}\right]-\xi f^{\prime}-\xi^{5 / 4} \frac{\gamma^{1 / 2} \operatorname{Pr}}{\operatorname{Pr}}\left(f^{\prime}\right)^{2} \\
=\frac{2(1-n)}{5 \varepsilon^{2} \operatorname{Pr}} \xi\left(f^{\prime} G^{\prime}-f^{\prime \prime} G\right) \\
\theta^{\prime \prime}+\frac{n+4}{5} f \theta^{\prime}+\frac{-1-4 n}{5} f^{\prime} \theta=\frac{2(1-n)}{5} \xi\left(f^{\prime} H-\theta^{\prime} G\right) \\
\frac{1}{S c} \phi^{\prime \prime}+\frac{n+4}{5 \operatorname{Pr}} f \phi^{\prime}+\kappa \frac{1}{N t+\theta} \theta^{\prime} \phi^{\prime}+\kappa \frac{1}{N t+\theta} \theta^{\prime \prime} \phi-\kappa\left(\frac{1}{N t+\theta}\right)^{2}\left(\theta^{\prime}\right)^{2} \phi \\
=\frac{2(1-n)}{5 \operatorname{Pr}} \xi\left(f^{\prime} I-\phi^{\prime} G\right) \\
\frac{1}{\varepsilon} G^{\prime \prime \prime}+H+N I-\frac{2(2 n+3)}{5 \varepsilon^{2} \operatorname{Pr}} f^{\prime} G^{\prime}+\frac{(n+4)}{5 \varepsilon^{2} \operatorname{Pr}}\left(f^{\prime \prime} G+f G^{\prime \prime}\right)-\left(f^{\prime}+\xi G^{\prime}\right) \\
-\frac{\gamma^{1 / 2}}{\operatorname{Pr}}\left[\frac{5}{4} \xi^{1 / 4}\left(f^{\prime}\right)^{2}+2 \xi^{5 / 4} f^{\prime} G^{\prime}\right]=\frac{2(1-n)}{5 \varepsilon^{2} \operatorname{Pr}}\left(f^{\prime} G^{\prime}-f^{\prime \prime} G\right) \\
H^{\prime \prime}+\frac{n+4}{5}\left(\theta^{\prime} G+f H^{\prime}\right)+\frac{-1-4 n}{5}\left(\theta G^{\prime}+f^{\prime} H\right)=\frac{2(1-n)}{5}\left(f^{\prime} H-\theta^{\prime} G\right)
\end{gathered}
$$




$$
\begin{aligned}
& \frac{1}{S c} I^{\prime \prime}+\frac{n+4}{5 \operatorname{Pr}}\left(\phi^{\prime} G+f I^{\prime}\right)+\kappa\left[\frac{\phi^{\prime} H^{\prime}}{(N t+\theta)}+\frac{\theta^{\prime} I^{\prime}}{(N t+\theta)}-\frac{\theta^{\prime} \phi^{\prime} H}{(N t+\theta)^{2}}\right]+\kappa\left[\frac{\phi H^{\prime \prime}}{(N t+\theta)}\right. \\
& \left.+\frac{\theta^{\prime \prime} I}{(N t+\theta)}-\frac{\theta^{\prime \prime} \phi H}{(N t+\theta)^{2}}\right]-\kappa\left[\frac{2 \theta^{\prime} \phi H^{\prime}}{(N t+\theta)^{2}}+\frac{\left(\theta^{\prime}\right)^{2} I}{(N t+\theta)^{2}}-\frac{2\left(\theta^{\prime}\right)^{2} \phi H}{(N t+\theta)^{3}}\right] \\
& =\frac{2(1-n)}{5 \operatorname{Pr}}\left(f^{\prime} I-\phi^{\prime} G\right)
\end{aligned}
$$

which constitute a system of ordinary differential equations. The associated boundary conditions are

$$
\begin{gathered}
f(\xi, 0)=f_{w} \quad f^{\prime}(\xi, 0)=0 \quad \theta^{\prime}(\xi, 0)=-1 \quad \phi(\xi, 0)=1 \\
f^{\prime}(\xi, \infty)=0 \quad \theta(\xi, \infty)=0 \quad \phi(\xi, \infty)=0 \\
G(\xi, 0)=0 \quad G^{\prime}(\xi, 0)=0 \quad H^{\prime}(\xi, 0)=0 \quad I(\xi, 0)=0 \\
G^{\prime}(\xi, \infty)=0 \quad H(\xi, \infty)=0 \quad I(\xi, \infty)=0
\end{gathered}
$$

The solutions are obtained by integrating numerically using the fourth-order RungeKutta method with the shooting technique. The grid mesh selected $\Delta \eta=0.01$ is used to obtain the numerical solution with the boundary condition as $\eta \rightarrow \infty$ approximated

\begin{tabular}{|c|c|c|c|c|c|}
\hline \multicolumn{6}{|c|}{ (a) } \\
\hline \multirow[t]{2}{*}{$N$} & \multirow[t]{2}{*}{ Le } & \multicolumn{2}{|c|}{$N u_{x} R a_{x}{ }^{-1 / 2}$} & \multicolumn{2}{|c|}{$S h_{x} R a_{x}{ }^{-1 / 2}$} \\
\hline & & Bejan and Khair [12] & Present Study & Bejan and Khair [12] & Present Study \\
\hline \multirow[t]{3}{*}{4} & 1 & 0.992 & 0.9922 & 0.992 & 0.9922 \\
\hline & 10 & 0.681 & 0.6810 & 3.290 & 3.2892 \\
\hline & 100 & 0.521 & 0.5208 & 10.521 & 10.5192 \\
\hline \multirow[t]{3}{*}{3} & 1 & 0.888 & 0.8875 & 0.888 & 0.8875 \\
\hline & 10 & 0.634 & 0.6345 & 2.973 & 2.9726 \\
\hline & 100 & 0.506 & 0.5064 & 9.532 & 9.5299 \\
\hline \multirow[t]{3}{*}{2} & 1 & 0.769 & 0.7686 & 0.769 & 0.7686 \\
\hline & 10 & 0.582 & 0.5824 & 2.617 & 2.6169 \\
\hline & 100 & 0.490 & 0.4899 & 8.424 & 8.4219 \\
\hline \multirow[t]{3}{*}{1} & 1 & 0.628 & 0.6275 & 0.628 & 0.6275 \\
\hline & 10 & 0.521 & 0.5214 & 2.202 & 2.2021 \\
\hline & 100 & 0.470 & 0.4700 & 7.139 & 7.1391 \\
\hline \multicolumn{6}{|c|}{ (b) } \\
\hline \multirow[t]{2}{*}{$N$} & $L e$ & \multicolumn{2}{|c|}{$N u_{x} R a_{x}^{-1 / 2}$} & \multicolumn{2}{|c|}{$S h_{x} R a_{x}{ }^{-1 / 2}$} \\
\hline & & Bejan and Khair [12] & Present Study & Bejan and Khair [12] & Present Study \\
\hline \multirow[t]{3}{*}{0} & 1 & 0.444 & 0.4437 & 0.444 & 0.4437 \\
\hline & 10 & 0.444 & 0.4438 & 1.680 & 1.6803 \\
\hline & 100 & 0.444 & 0.4438 & 5.544 & 5.5448 \\
\hline-1 & & - & - & - & - \\
\hline-2.0 & 1 & 0.444 & 0.4437 & 0.444 & 0.4437 \\
\hline \multirow[t]{2}{*}{-3.0} & 1 & 0.628 & 0.6275 & 0.628 & 0.6275 \\
\hline & 2 & 0.488 & 0.4834 & 0.832 & 0.8324 \\
\hline \multirow[t]{2}{*}{-4.0} & 1 & 0.769 & 0.7686 & 0.769 & 0.7686 \\
\hline & 2 & 0.627 & 0.6266 & 1.046 & 1.0455 \\
\hline \multirow[t]{2}{*}{-5.0} & 1 & 0.888 & 0.8875 & 0.888 & 0.8875 \\
\hline & 2 & 0.739 & 0.7390 & 1.220 & 1.2202 \\
\hline
\end{tabular}
by $\eta_{\max }=6.0$, which is sufficiently large to approach the relevant stream velocity. To confirm the numerical skills, we compared the local Nusselt and Sherwood numbers with a previous study from Bejan and Khair [12]. Table 1 presents the comparison data for various values of buoyancy ratio $N$ and Lewis number $L e$; the results are in good agreement.

Table 1. Comparison of the values of the local Nusselt and Sherwood numbers with Bejan and Khair [12] for various parameters of $N$ and Le. 
Figure 2a-c shows the effect of suction/blowing strength on the velocity, temperature, and concentration distributions. Because the suction effect will decrease the flow velocity and lead the maximum velocity to approach the wall surface, the suction/blowing parameter increases with decreasing maximum fluid velocity and temperature. It could also be seen that the zone in the concentration boundary layer becomes thinner for the larger suction/blowing parameter. Figure $3 \mathrm{a}-\mathrm{c}$ shows the results of the inertia effect on the velocity, temperature, and concentration profiles for different values of $\gamma$. The velocity increases, but the temperature and concentration profiles decrease with increasing $\gamma$. As the $\gamma$ value increases, i.e., the permeability increases, the flow velocity becomes faster, bringing the warm fluid and species away from the wall to get a lower temperature and concentration. Parameter $N$ denotes the buoyancy ratio intensity produced from the concentration expansion to the thermal one. Figure 4a-c shows the effects of the buoyancy ratio $N$ on velocity, temperature, and concentration. Positive $N$ values indicate the buoyancy forces by concentration and thermal expansions are in the same direction and enhance the flow speed, whereas negative $N$ values indicate the opposite flow conditions. Increasing the buoyancy ratio will increase the buoyancy-induced flow velocity and decrease the temperature and concentration.

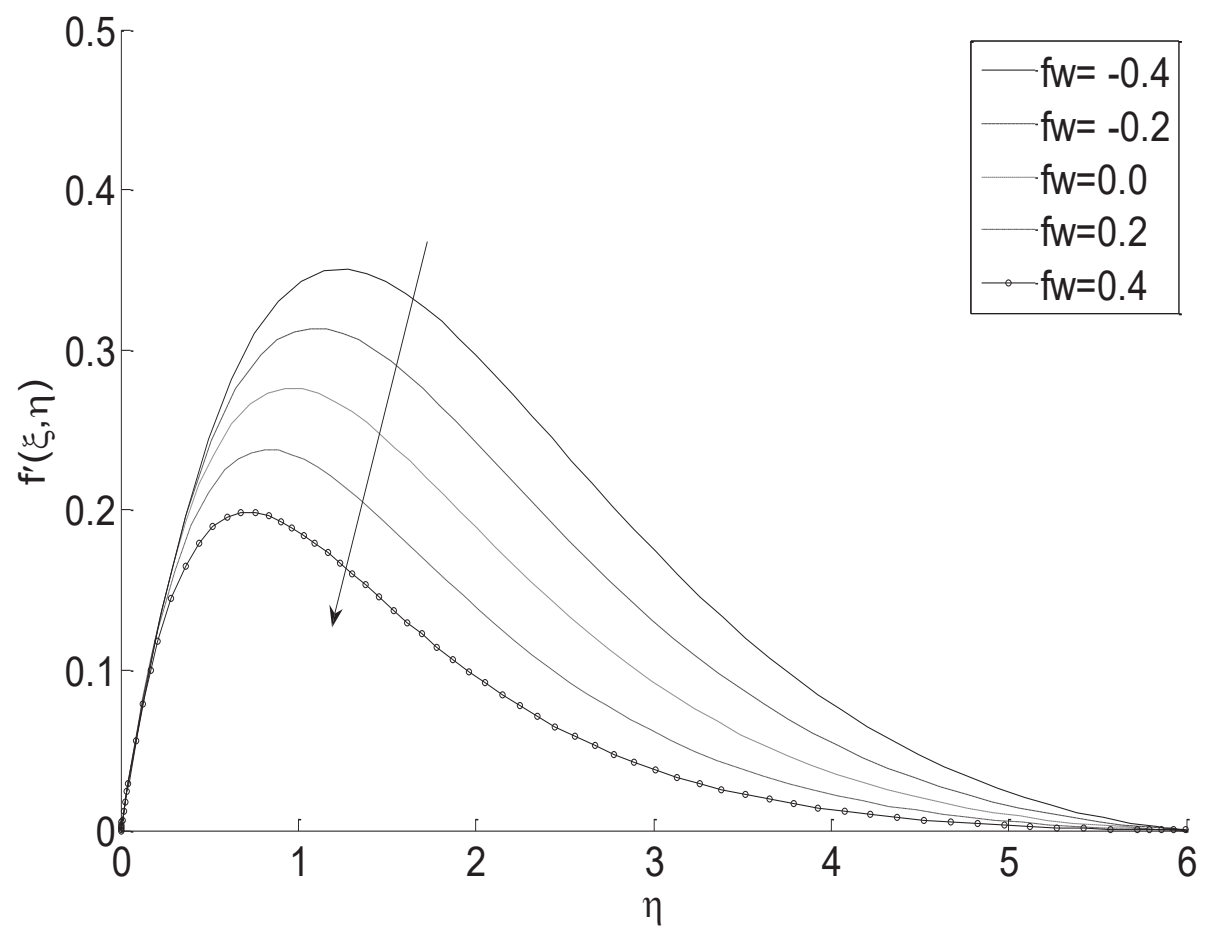

(a)

Figure 2. Cont. 


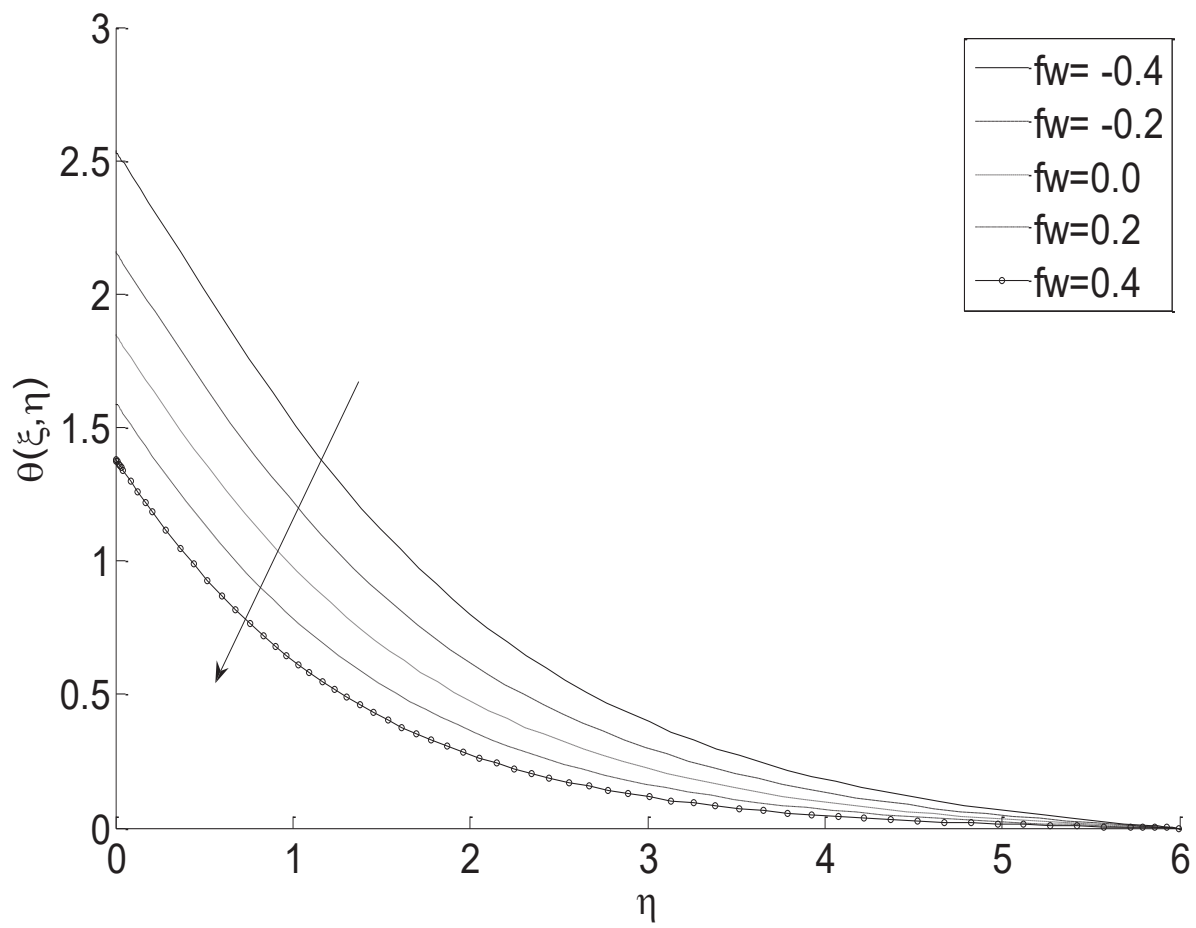

(b)

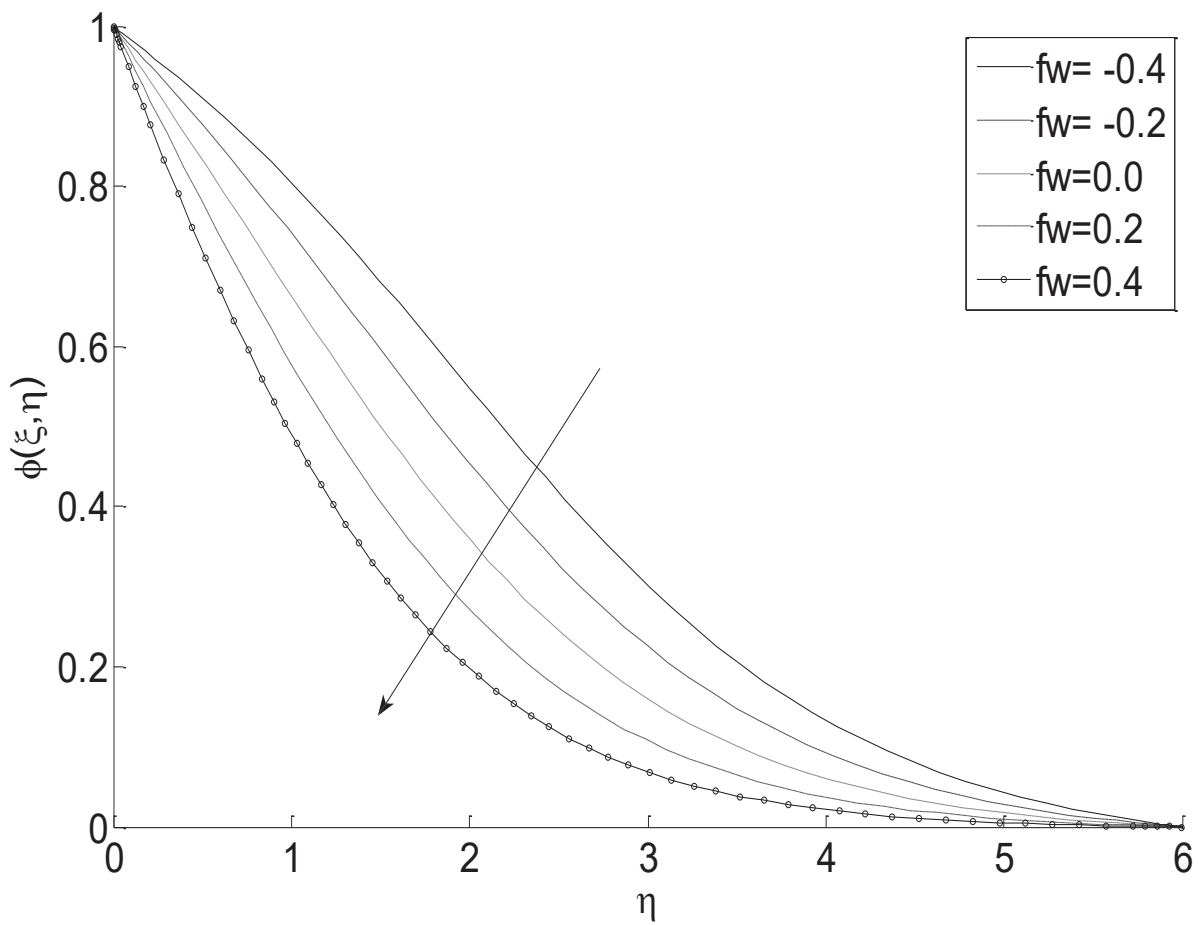

(c)

Figure 2. (a-c) Velocity, temperature, and concentration profiles, respectively, with different suction/blowing parameters at $\xi=1.0, n=1.0, S c=1.0, N=1.0, \gamma=2.01, \varepsilon=0.45, \kappa=0.5$, and $N t=1.0$. 


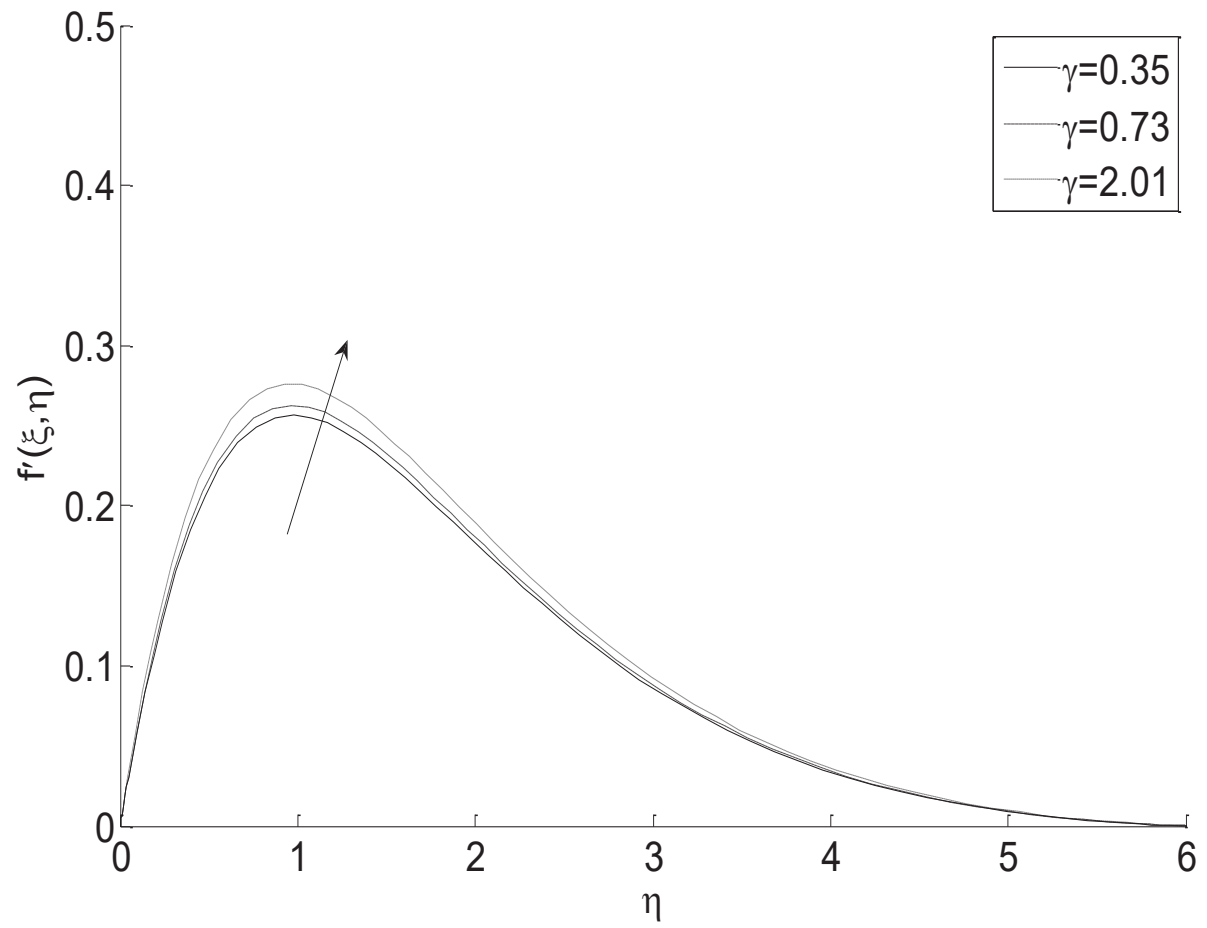

(a)

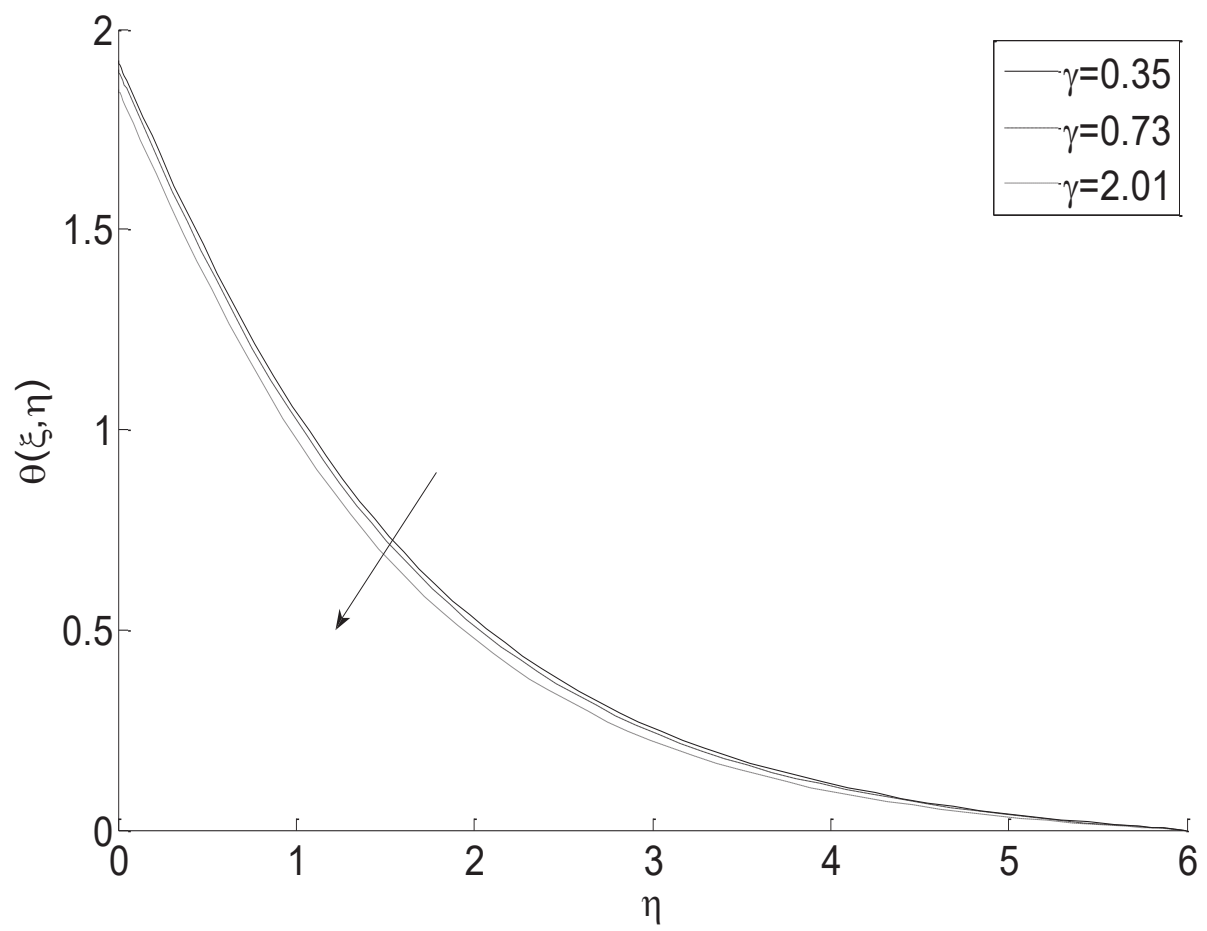

(b)

Figure 3. Cont. 


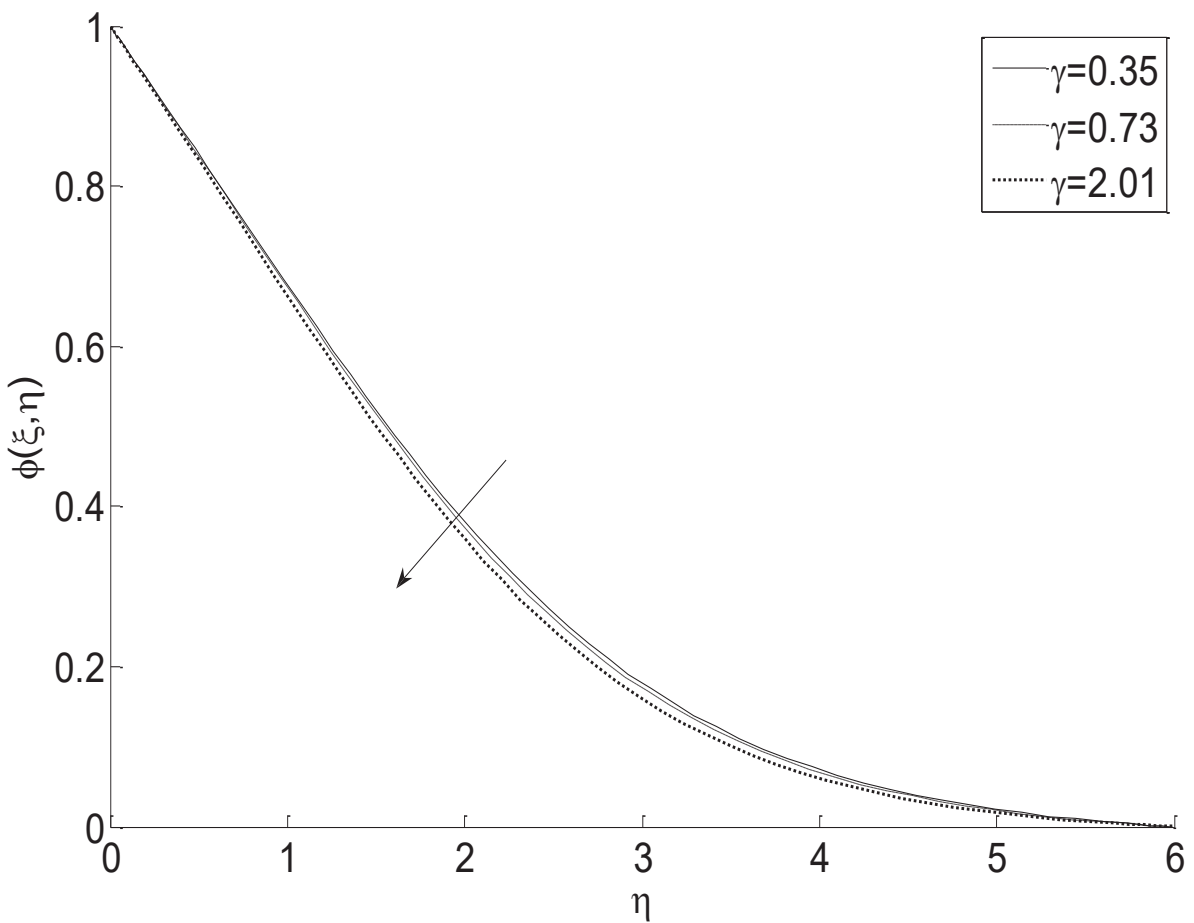

(c)

Figure 3. (a-c) Velocity, temperature, and concentration profiles, respectively, with different inertia parameters at $\xi=1.0, n=1.0, S c=1.0, N=1.0, f_{w}=0.0, \kappa=0.5$, and $N t=1.0$.

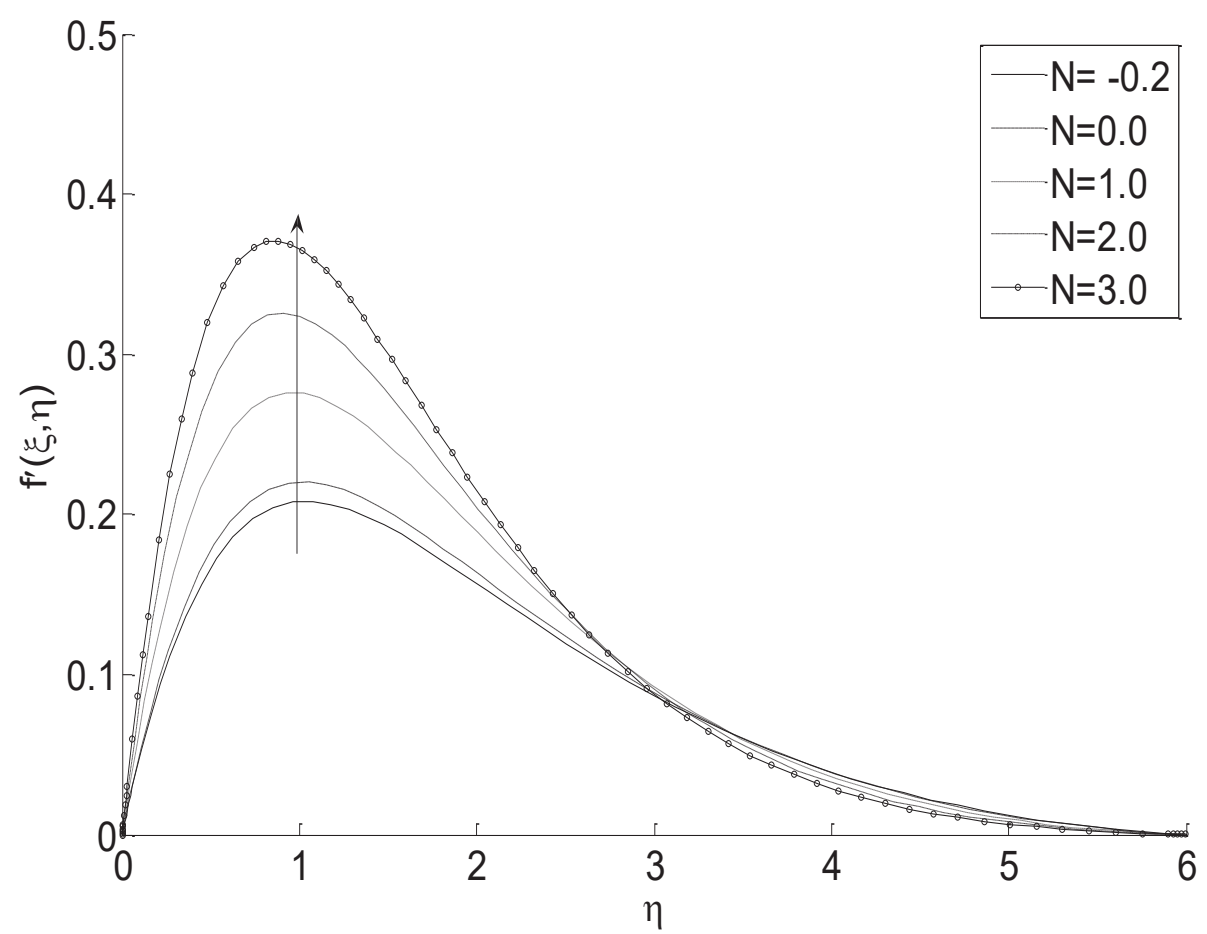

(a)

Figure 4. Cont. 


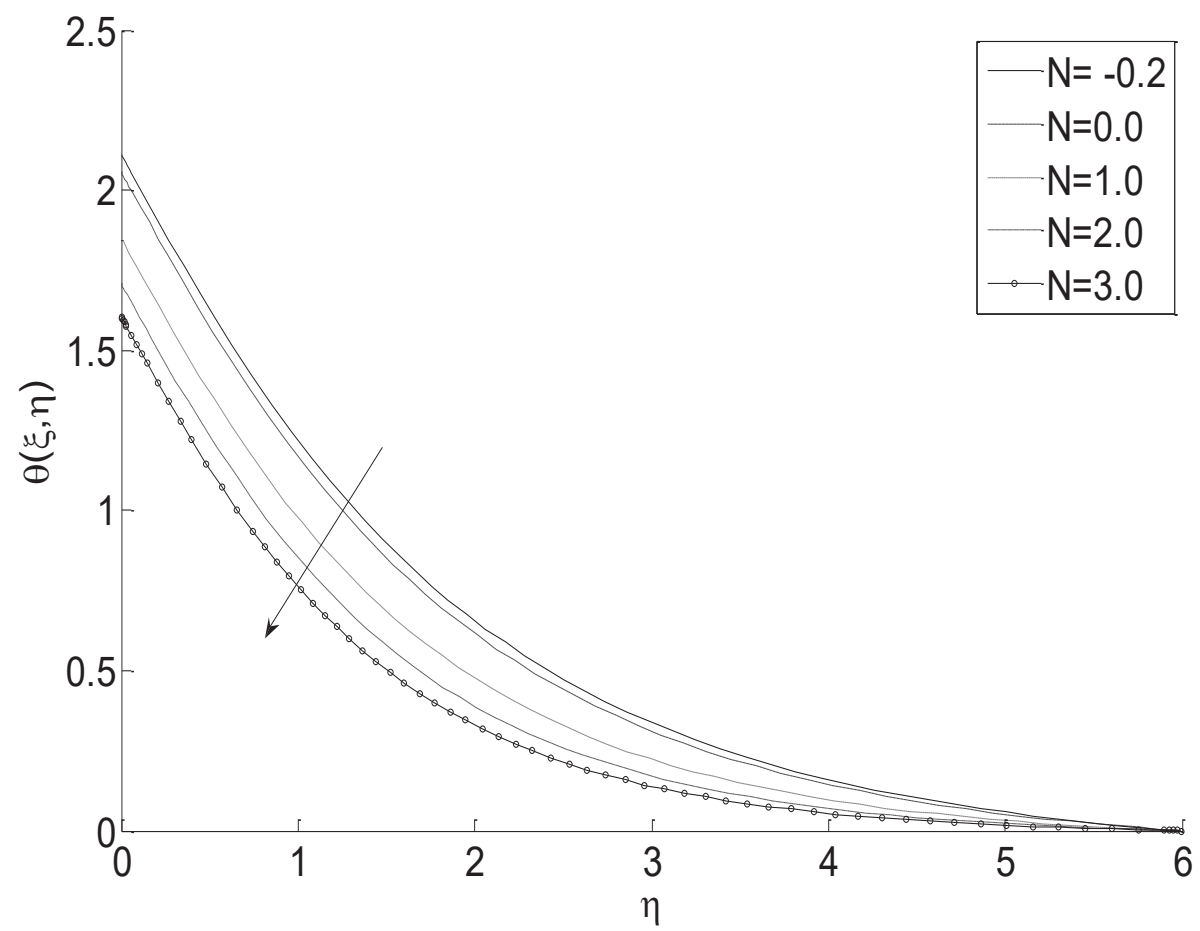

(b)

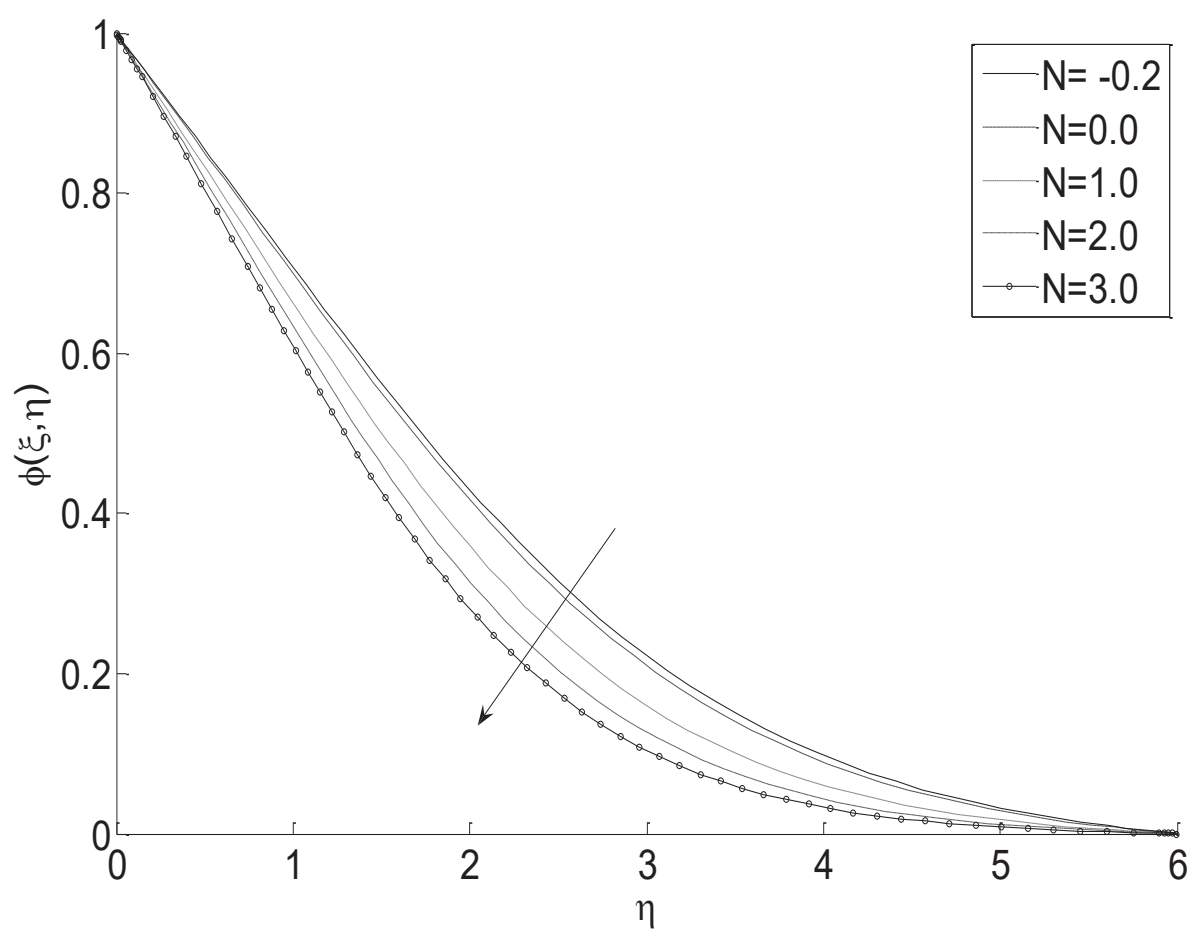

(c)

Figure 4. (a-c) Velocity, temperature, and concentration profiles, respectively, with different buoyancy ratio at $\xi=1.0, n=1.0, S c=1.0, \gamma=2.01, \varepsilon=0.45, f_{w}=0.0, \kappa=0.5$, and $N t=1.0$.

To examine the effect of the power-law exponent of heat flux, the thermophoretic parameter and position function were selected, $N t=1.0$ at $\xi=1.0$, corresponding to the constant characteristic temperature $T^{*}$ at a fixed position. Figure $5 \mathrm{a}-\mathrm{c}$ shows the velocity, temperature, and concentrations profiles for various $n$. It could be seen that the changes in profiles are more obvious for smaller $n$ because a larger temperature gradient near-wall 
correspond to a thinner concentration boundary layer. Figure $6 \mathrm{a}-\mathrm{c}$ shows the effects of varying the position $\xi$ on the velocity, temperature, and concentration distribution. This figure shows how the profiles vary with $\xi$, the scaled streamwise coordinate. As shown in the figure, relative to a constant $\eta$, the velocity decreases with an increasing $\xi$, representing far from the leading edge. As the fluid flows through the porous medium, the pressure drag would retard the flow and hence increase the temperature and concentration. Figure 7 shows the concentration profiles for the selected Schmidt numbers from 0.5 to 2.5. The larger Schmidt number represents the species with smaller gas diffusivity, resulting in a thinner concentration boundary layer. Figure 8 shows the thermophoretic effect on the mass concentration. A larger $N t$ value with $T_{\infty}$ remains a constant, indicating a weaker strength of wall heat source and resulting in a smaller temperature gradient in the $y$ direction. Hence, making the concentration boundary layer closer to the wall surface.

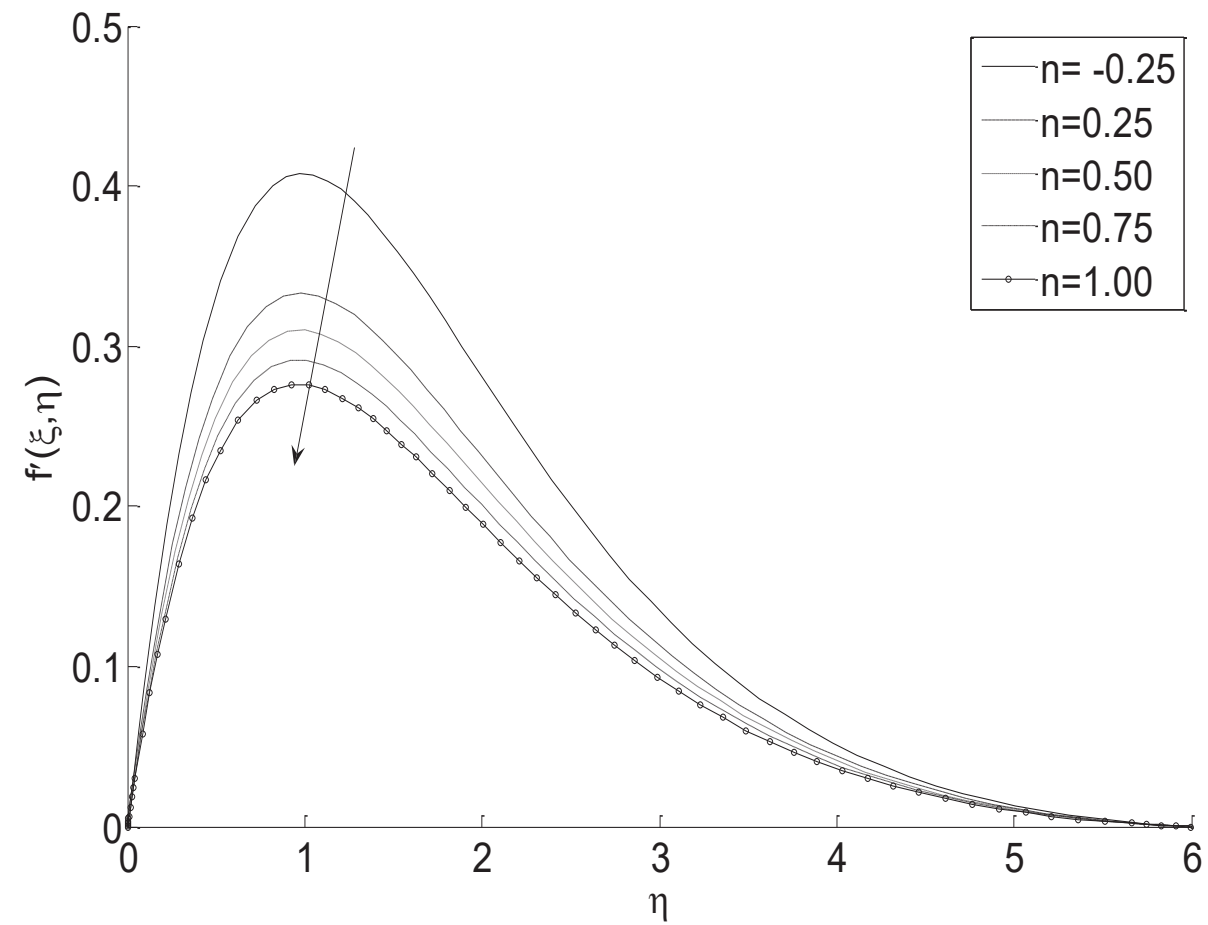

(a)

Figure 5. Cont. 


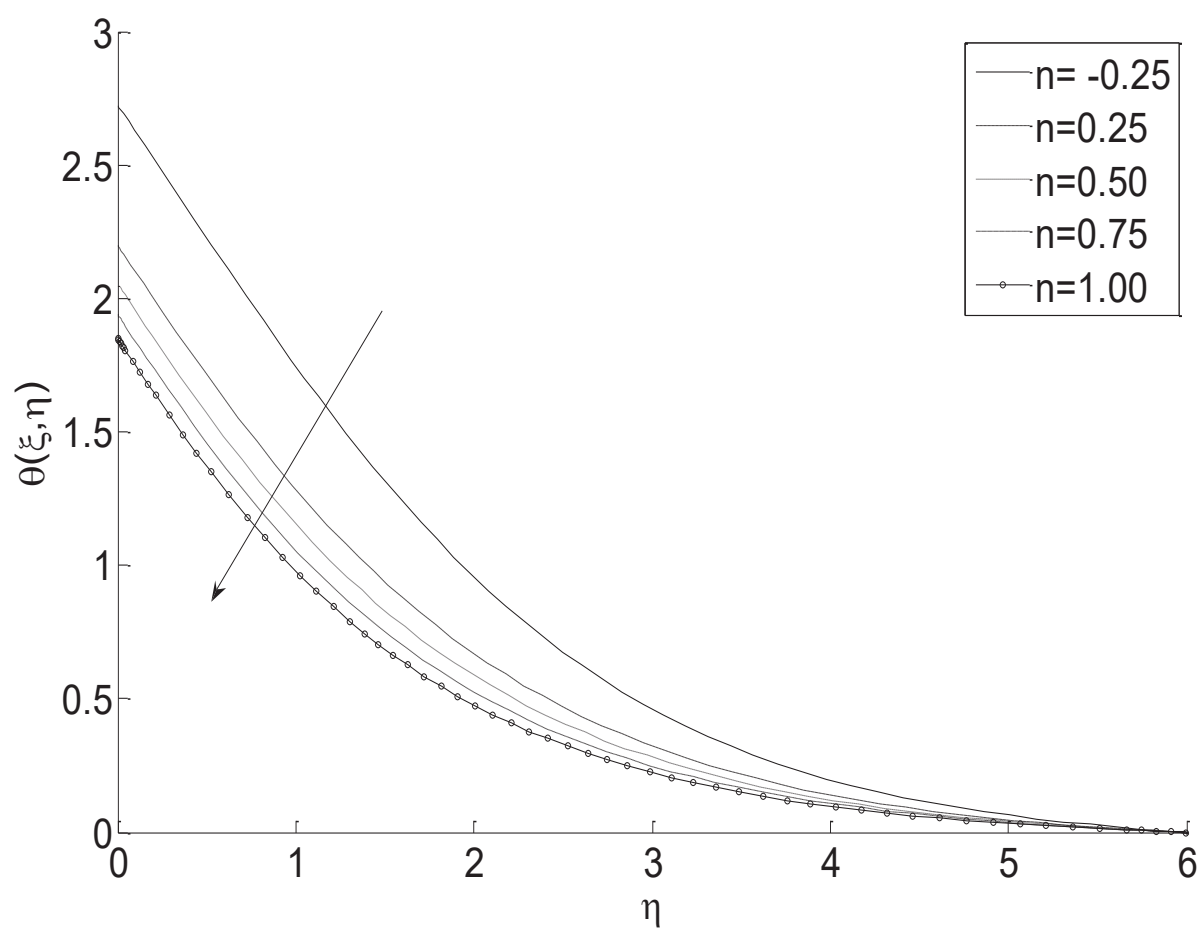

(b)

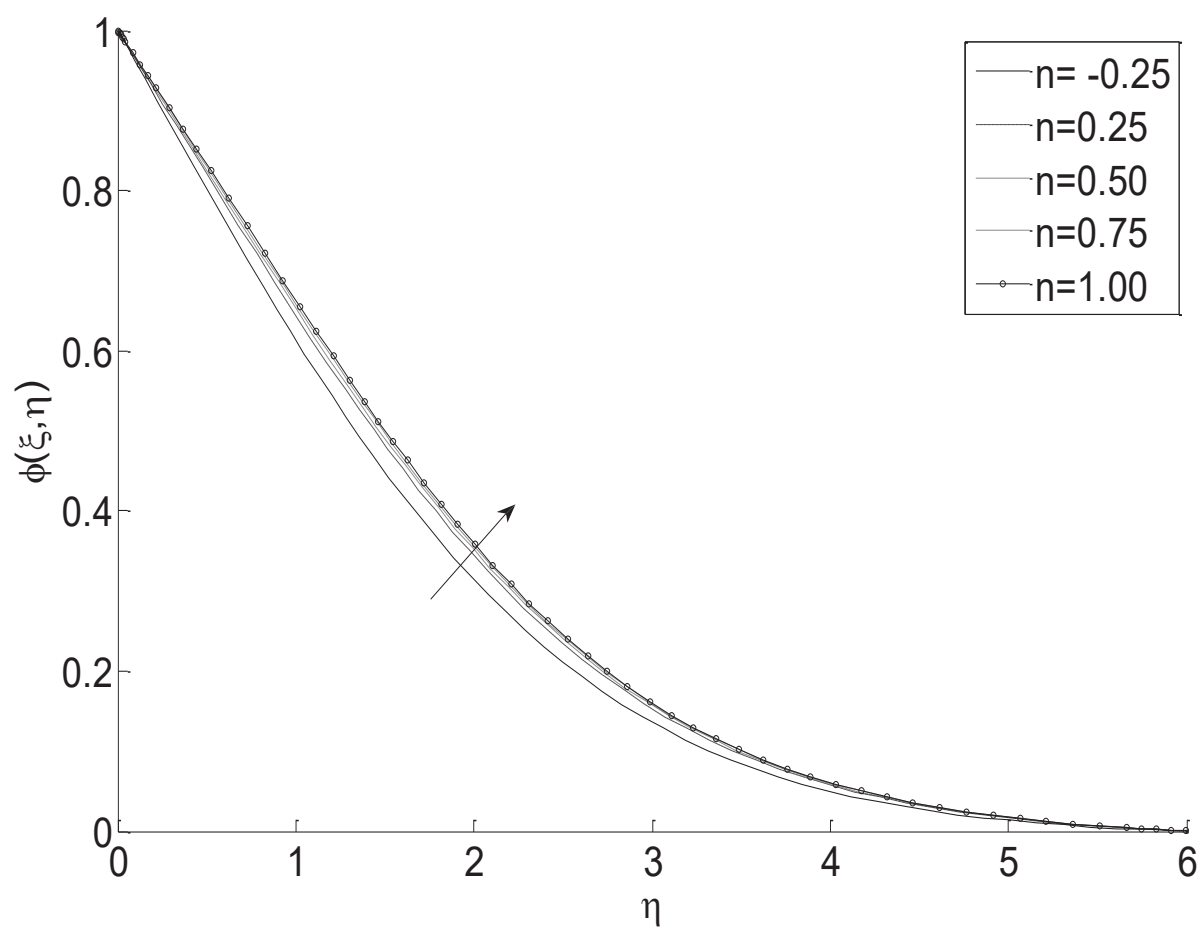

(c)

Figure 5. (a-c) Velocity, temperature, and concentration profiles, respectively, with different exponents of heat flux at $\xi=1.0, S c=1.0, N=1.0, \gamma=2.01, \varepsilon=0.45, f_{w}=0.0, \kappa=0.5$, and $N t=1.0$. 


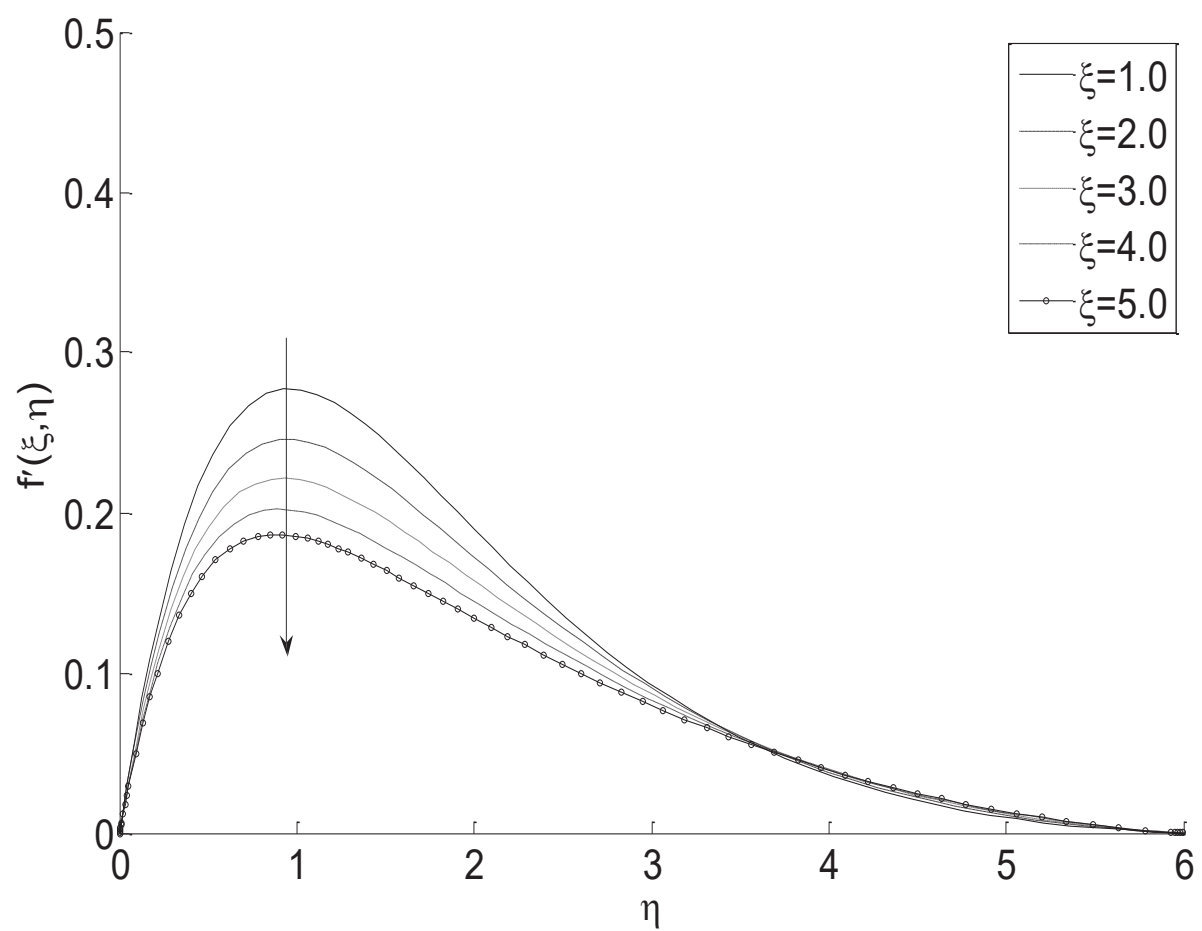

(a)

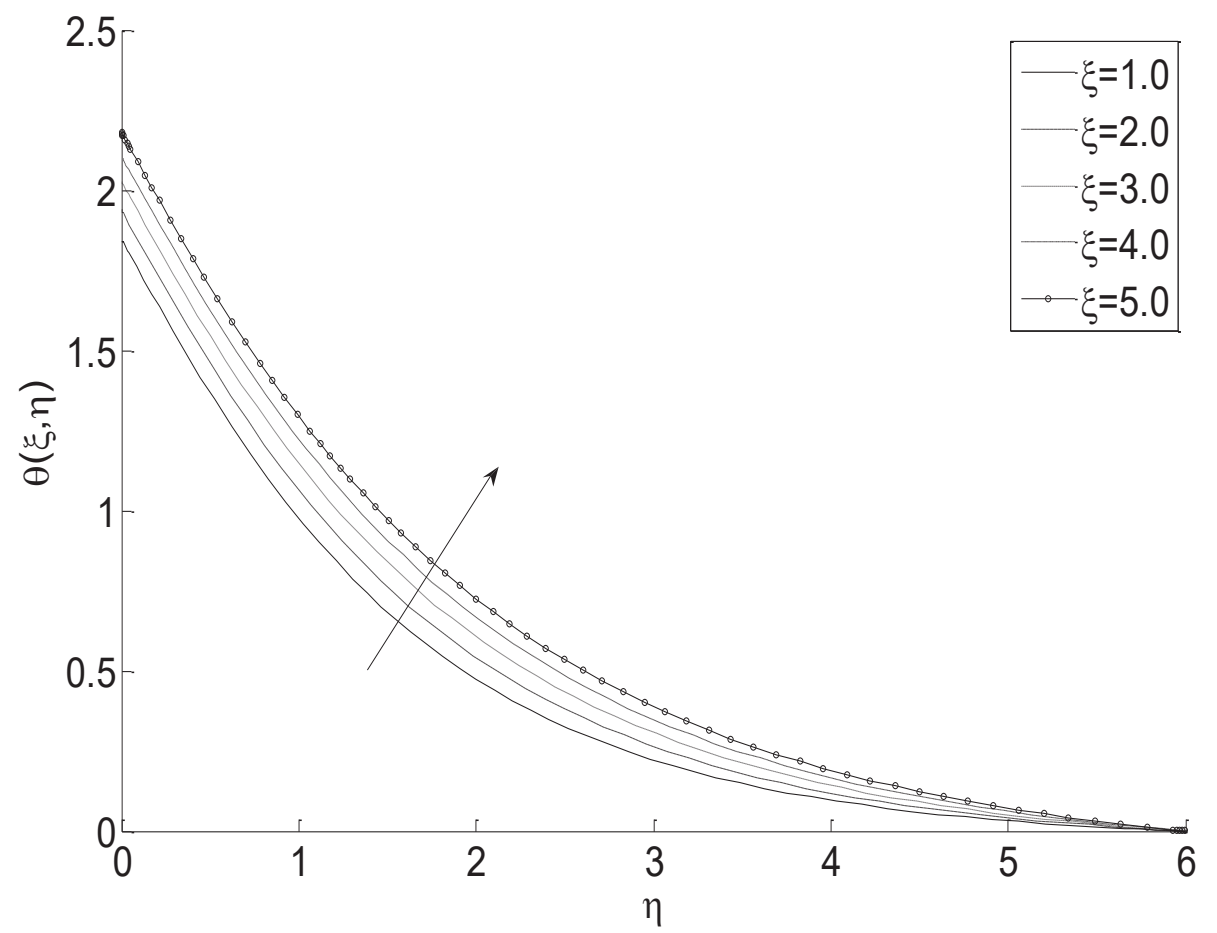

(b)

Figure 6. Cont. 


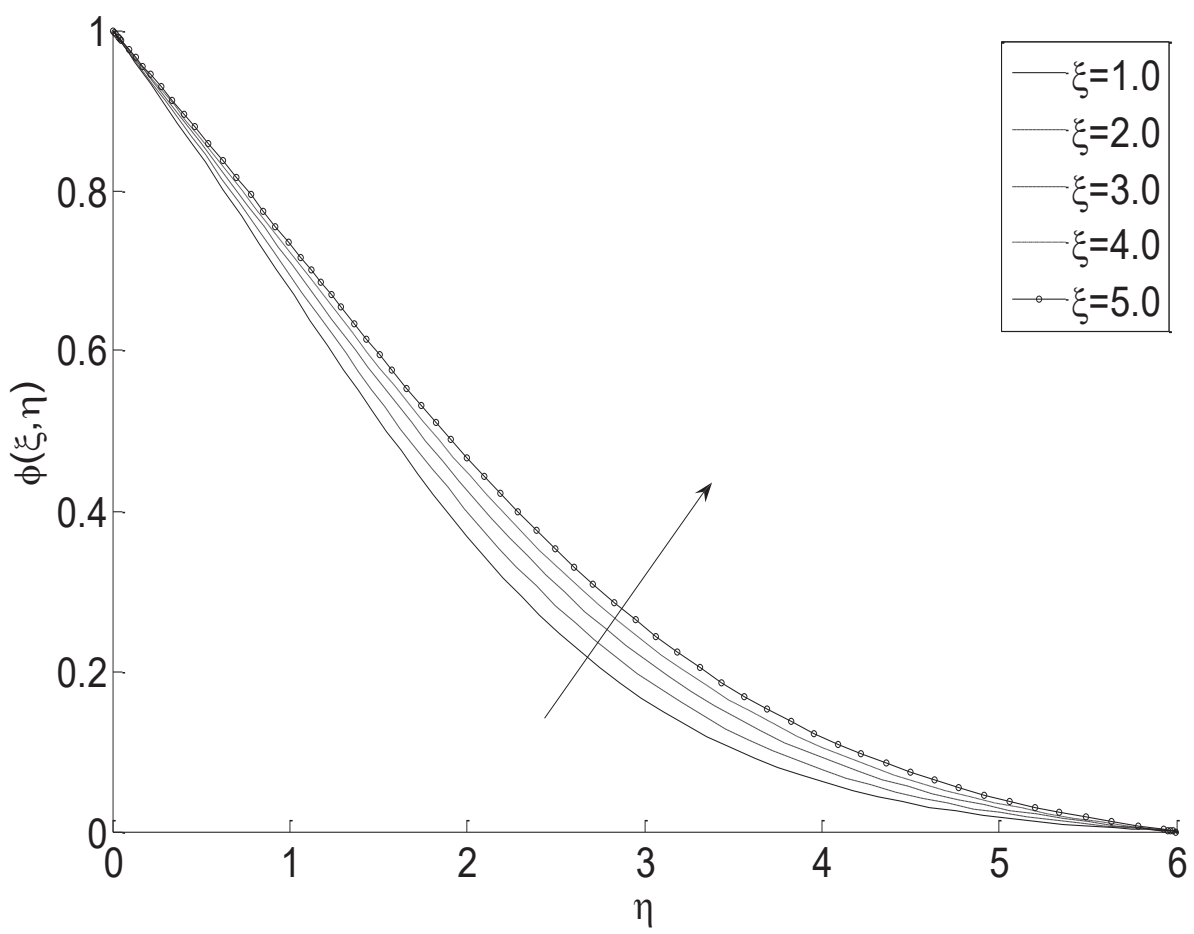

(c)

Figure 6. (a-c) Velocity, temperature, and concentration profiles, respectively, with different position parameters at $n=1.0, S c=1.0, N=1.0, \gamma=2.01, \varepsilon=0.45, f_{w}=0.0, \kappa=0.5$, and $N t=1.0$.

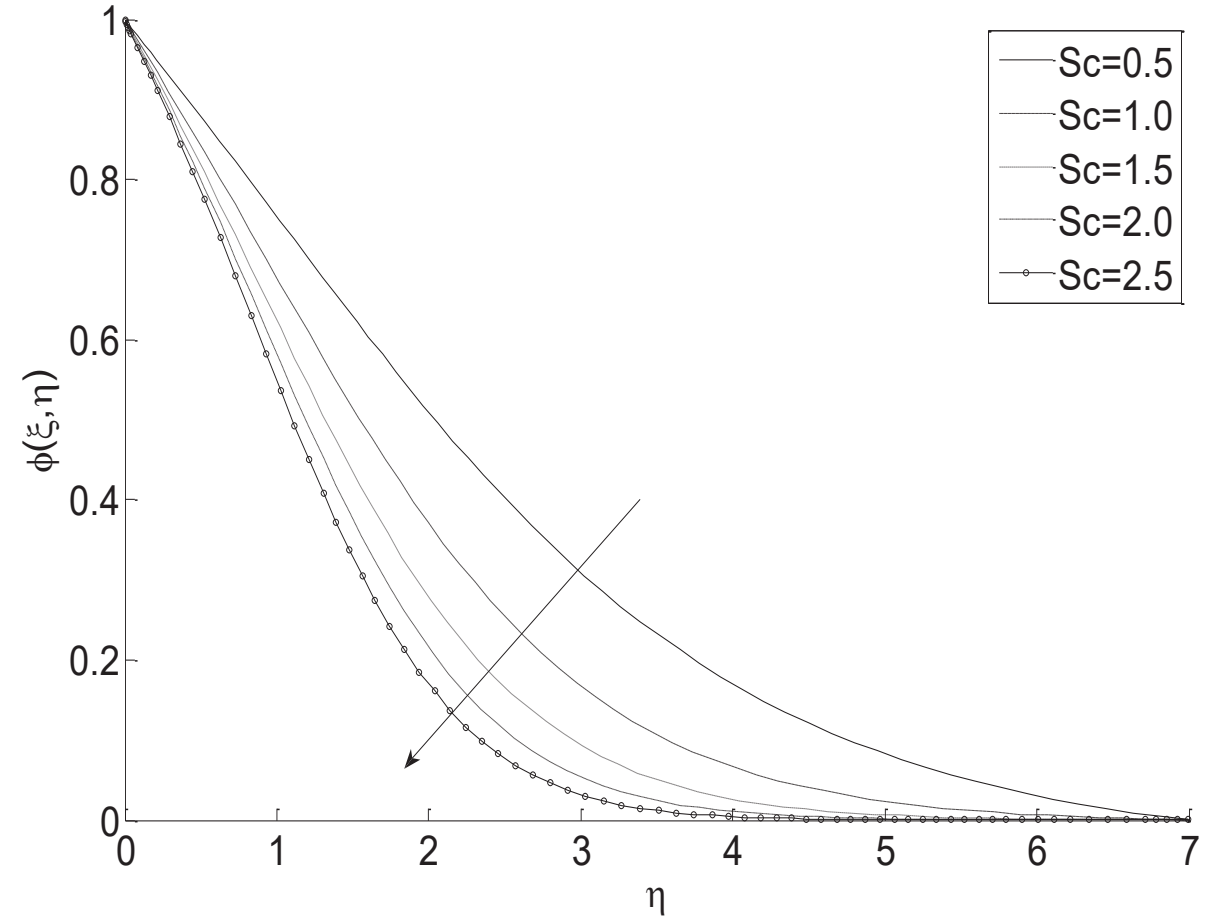

Figure 7. Concentration profiles for different Schmidt numbers at $\xi=1.0, n=1.0, N=1.0, \gamma=2.01$, $\varepsilon=0.45, f_{w}=0.0, \kappa=0.5$, and $N t=1.0$. 


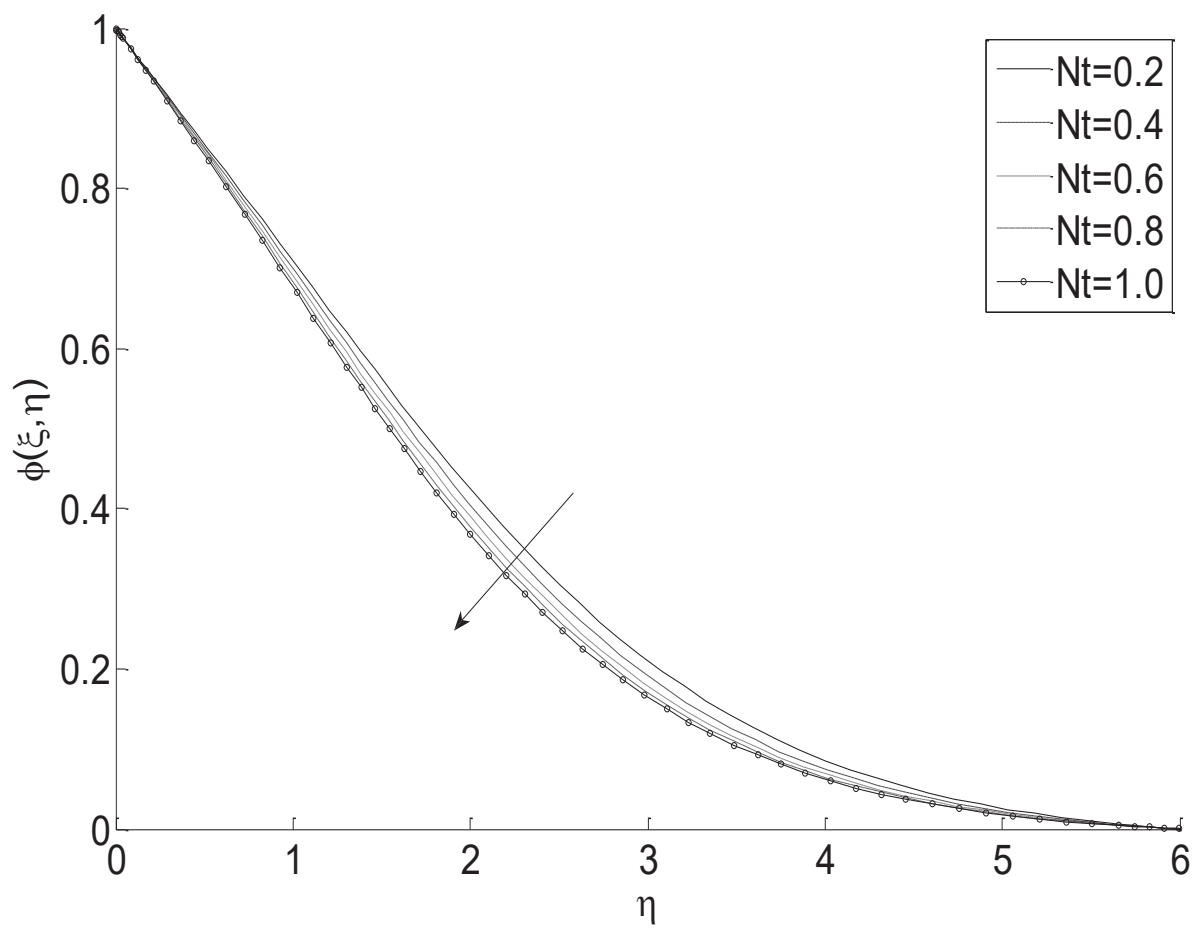

Figure 8. Concentration profiles for different thermophoretic parameters at $\xi=1.0, n=1.0, S c=1.0$, $N=1.0, \gamma=2.01, \varepsilon=0.45, f_{w}=0.0$, and $\kappa=0.5$.

Figure 9 shows the mass transfer conductance under suction and blowing velocity on different Schmidt numbers. The zero-mass transfer limiting $g_{m x}^{*}$ indicates the mass transfer conductance for $f_{w}=0$. It is seen that the surface blowing effect decreases the mass transfer, but enhances for suction. Figure $10 \mathrm{a}, \mathrm{b}$ shows the calculated value of the local Nusselt number $N u_{x} / R a_{x}{ }^{1 / 5}$ and Sherwood number $S h_{x} / R a_{x}{ }^{1 / 5}$, denoting the slope of the temperature and concentration profiles at the wall surface. The thermophoretic effect on $S h_{x} / R a_{x}{ }^{1 / 5}$ under different buoyancy ratios reveals that $S h_{x} / R a_{x}{ }^{1 / 5}$ increases with increasing $N t$ and $N$ values. Tables 2-8 present the predicted results of wall shear stress, temperature, and mass transfer rate for each set of parameters $f_{w}, \gamma, N, n, \xi$, Sc, and $N t$. The concentration gradient $\phi^{\prime}(\xi, 0)$ can be used to determine the wall mass flux from Equation (19) for gas diffusing into the air through a porous medium.

Table 2. Solutions of $f^{\prime \prime}(1,0), \theta(1,0)$, and $\phi^{\prime}(1,0)$ for various values of $f_{w}$ at $n=1.0, S_{c}=1.0, N=1.0$, $\gamma=2.01, \varepsilon=0.45, \kappa=0.5$, and $N t=1.0$.

\begin{tabular}{lccc}
\hline$f_{w}$ & $f^{\prime \prime}(1,0)$ & $\boldsymbol{\theta}(1,0)$ & $\boldsymbol{\phi}^{\prime}(1,0)$ \\
\hline-0.4 & 0.6761 & 2.5137 & -0.1469 \\
-0.2 & 0.7098 & 2.1416 & -0.2148 \\
0.0 & 0.7411 & 1.8374 & -0.3129 \\
0.2 & 0.7594 & 1.5874 & -0.4432 \\
0.4 & 0.7540 & 1.3779 & -0.6040 \\
\hline
\end{tabular}

Table 3. Solutions of $f^{\prime \prime}(1,0), \theta(1,0)$, and $\phi^{\prime}(1,0)$ for various values of $\gamma$ at $n=1.0, S c=1.0, N=1.0$, $f_{w}=0.0, \kappa=0.5$, and $N t=1.0$.

\begin{tabular}{llll}
\hline$\gamma$ & $f^{\prime \prime}(1,0)$ & $\boldsymbol{\theta}(1,0)$ & $\boldsymbol{\phi}^{\prime}(1,0)$ \\
\hline 0.35 & 0.6664 & 1.9144 & -0.2985 \\
0.73 & 0.6885 & 1.8899 & -0.3030 \\
2.01 & 0.7411 & 1.8374 & -0.3129 \\
\hline
\end{tabular}


Table 4. Solutions of $f^{\prime \prime}(1,0), \theta(1,0)$, and $\phi^{\prime}(1,0)$ for various values of $N$ at $n=1.0, S c=1.0, \gamma=2.01$, $\varepsilon=0.45, f_{w}=0.0, \kappa=0.5$, and $N t=1.0$.

\begin{tabular}{lccc}
\hline $\boldsymbol{N}$ & $f^{\prime \prime}(1,0)$ & $\boldsymbol{\theta}(1,0)$ & $\boldsymbol{\phi}^{\prime}(1,0)$ \\
\hline-0.2 & 0.5208 & 2.1043 & -0.2703 \\
0.0 & 0.5569 & 2.0489 & -0.2781 \\
1.0 & 0.7411 & 1.8374 & -0.3129 \\
2.0 & 0.9248 & 1.6952 & -0.3419 \\
3.0 & 1.1043 & 1.5919 & -0.3665 \\
\hline
\end{tabular}

Table 5. Solutions of $f^{\prime \prime}(1,0), \theta(1,0)$, and $\phi^{\prime}(1,0)$ for various values of $n$ at $S c=1.0, N=1.0, \gamma=2.01$, $\varepsilon=0.45, f_{w}=0.0, \kappa=0.5$, and $N t=1.0$.

\begin{tabular}{lccc}
\hline $\boldsymbol{n}$ & $\boldsymbol{f}^{\prime}(1,0)$ & $\boldsymbol{\theta}(1,0)$ & $\boldsymbol{\phi}^{\prime}(1,0)$ \\
\hline-0.25 & 1.0482 & 2.6652 & -0.3646 \\
0.25 & 0.8698 & 2.1699 & -0.3319 \\
0.50 & 0.8166 & 2.0297 & -0.3232 \\
0.75 & 0.7749 & 1.9226 & -0.3172 \\
1.00 & 0.7411 & 1.8374 & -0.3129 \\
\hline
\end{tabular}

Table 6. Solutions of $f^{\prime \prime}(\xi, 0), \theta(\xi, 0)$, and $\phi^{\prime}(\xi, 0)$ for various values of $\xi$ at $n=1.0, S c=1.0, N=1.0$, $\gamma=2.01, \varepsilon=0.45, f_{w}=0.0, \kappa=0.5$, and $N t=1.0$.

\begin{tabular}{lccc}
\hline$\xi$ & $f^{\prime \prime}(\xi, 0)$ & $\boldsymbol{\theta}(\boldsymbol{\xi}, 0)$ & $\boldsymbol{\phi}^{\prime}(\boldsymbol{\xi}, 0)$ \\
\hline 1.0 & 0.7411 & 1.8374 & -0.3129 \\
2.0 & 0.6986 & 1.9229 & -0.2963 \\
3.0 & 0.6648 & 2.0030 & -0.2824 \\
4.0 & 0.6374 & 2.0773 & -0.2707 \\
5.0 & 0.6147 & 2.1464 & -0.2609 \\
\hline
\end{tabular}

Table 7. Solutions of $f^{\prime \prime}(1,0), \theta(1,0)$, and $\phi^{\prime}(1,0)$ for various values of $S c$ at $n=1.0, N=1.0, \gamma=2.01$, $\varepsilon=0.45, f_{w}=0.0, \kappa=0.5$, and $N t=1.0$.

\begin{tabular}{lccc}
\hline$S c$ & $f^{\prime \prime}(1,0)$ & $\boldsymbol{\theta}(1,0)$ & $\boldsymbol{\phi}^{\prime}(1,0)$ \\
\hline 0.5 & 0.7473 & 1.8027 & -0.2439 \\
1.0 & 0.7421 & 1.8383 & -0.3120 \\
1.5 & 0.7384 & 1.8611 & -0.3562 \\
2.0 & 0.7356 & 1.8764 & -0.3858 \\
2.5 & 0.7334 & 1.8873 & -0.4061 \\
\hline
\end{tabular}

Table 8. Solutions of $f^{\prime \prime}(1,0), \theta(1,0)$, and $\phi^{\prime}(1,0)$ for various values of $N t$ at $n=1.0, S c=1.0, N=1.0$, $\gamma=2.01, \varepsilon=0.45, f_{w}=0.0$, and $\kappa=0.5$.

\begin{tabular}{lccc}
\hline $\boldsymbol{N} \boldsymbol{t}$ & $\boldsymbol{f}^{\prime \prime}(1,0)$ & $\boldsymbol{\theta}(1,0)$ & $\boldsymbol{\phi}^{\prime}(1,0)$ \\
\hline 0.2 & 0.7434 & 1.8245 & -0.2933 \\
0.4 & 0.7429 & 1.8290 & -0.2967 \\
0.6 & 0.7422 & 1.8325 & -0.3019 \\
0.8 & 0.7417 & 1.8352 & -0.3075 \\
1.0 & 0.7411 & 1.8374 & -0.3129 \\
\hline
\end{tabular}




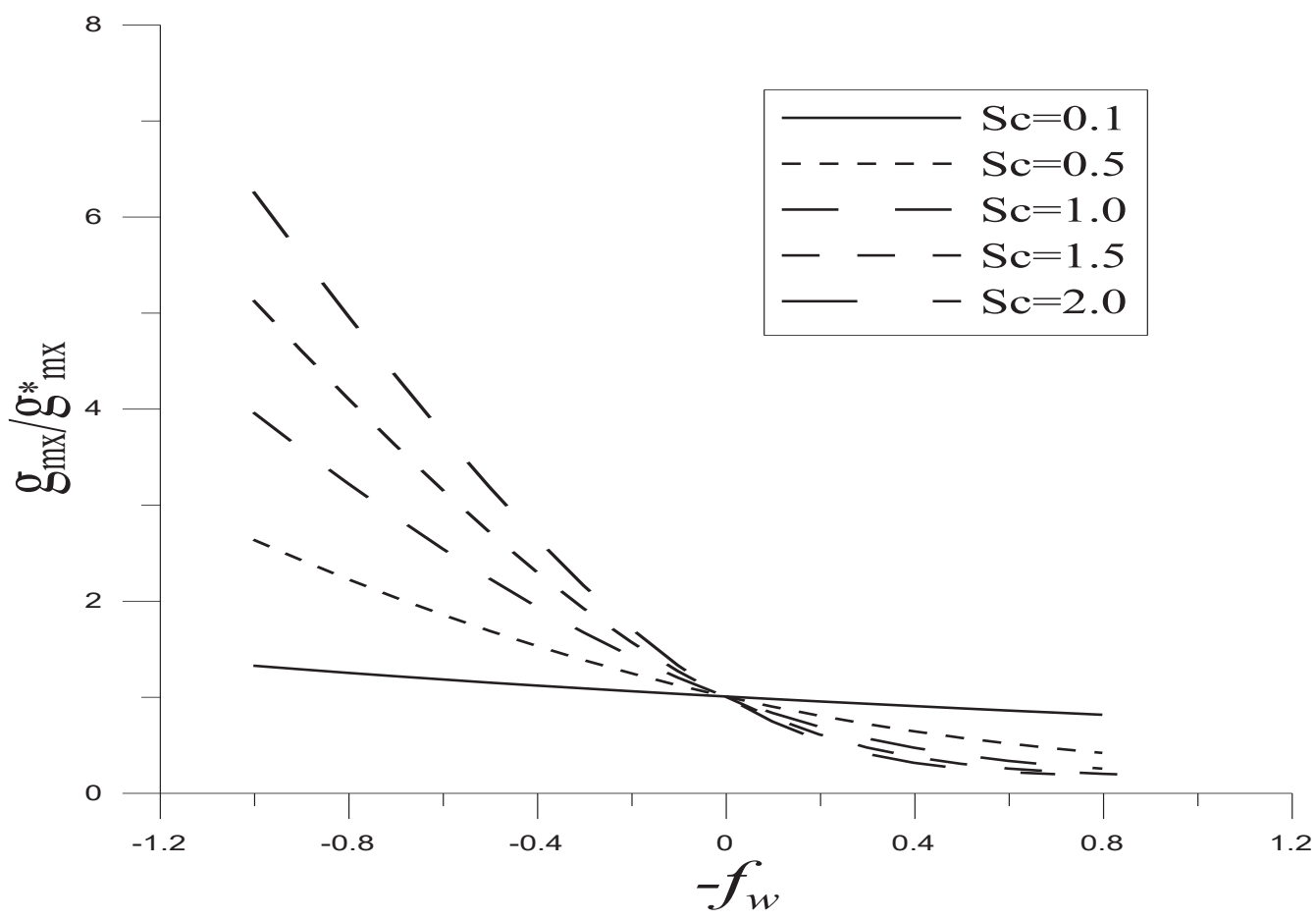

Figure 9. Ratio of mass fluxes with various values of $S c$ and $f_{w}$ at $\xi=1.0, n=1.0, N=1.0, \gamma=2.01$, $\varepsilon=0.45, N t=1.0$, and $\kappa=0.5$. 


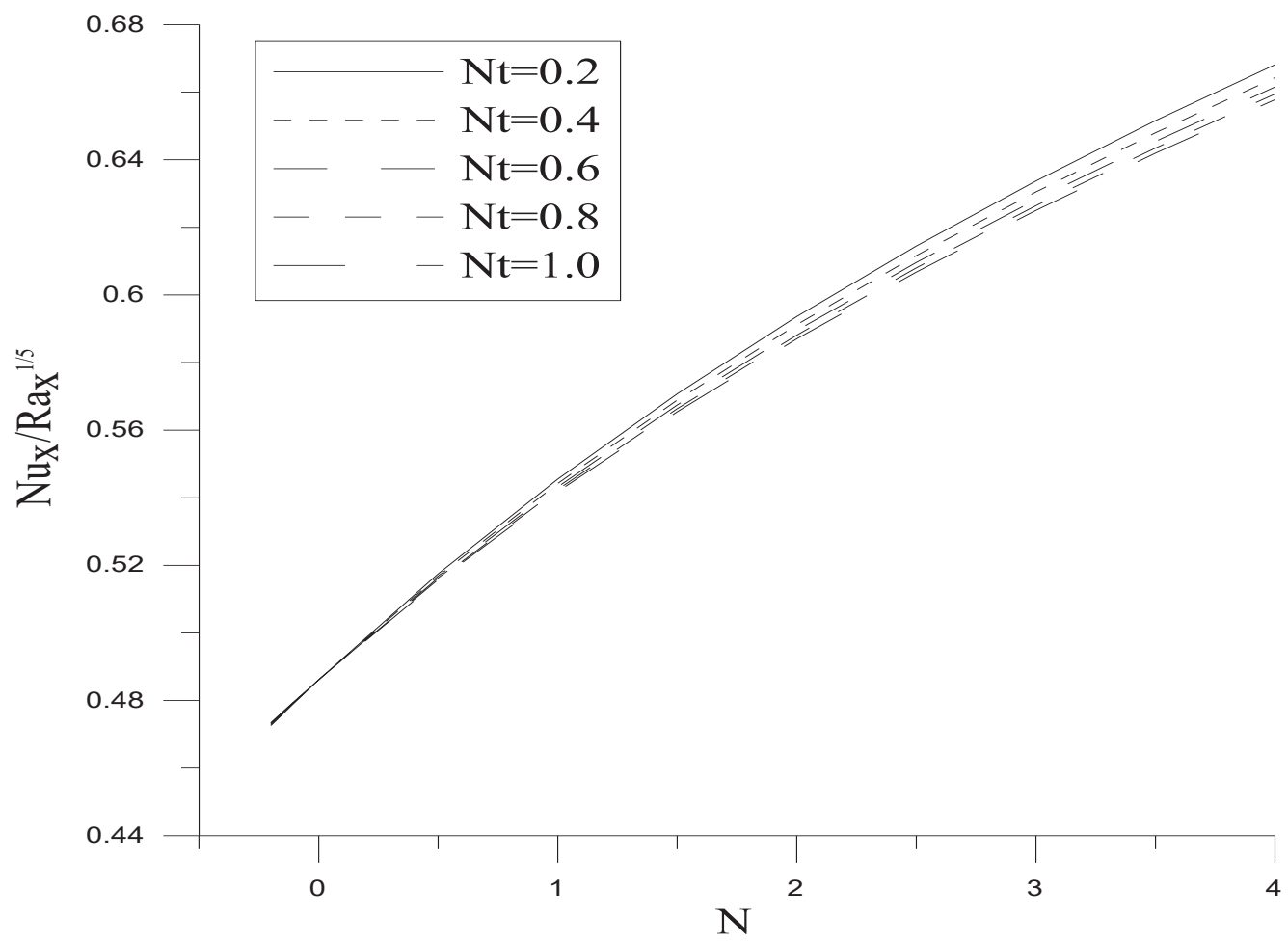

(a)

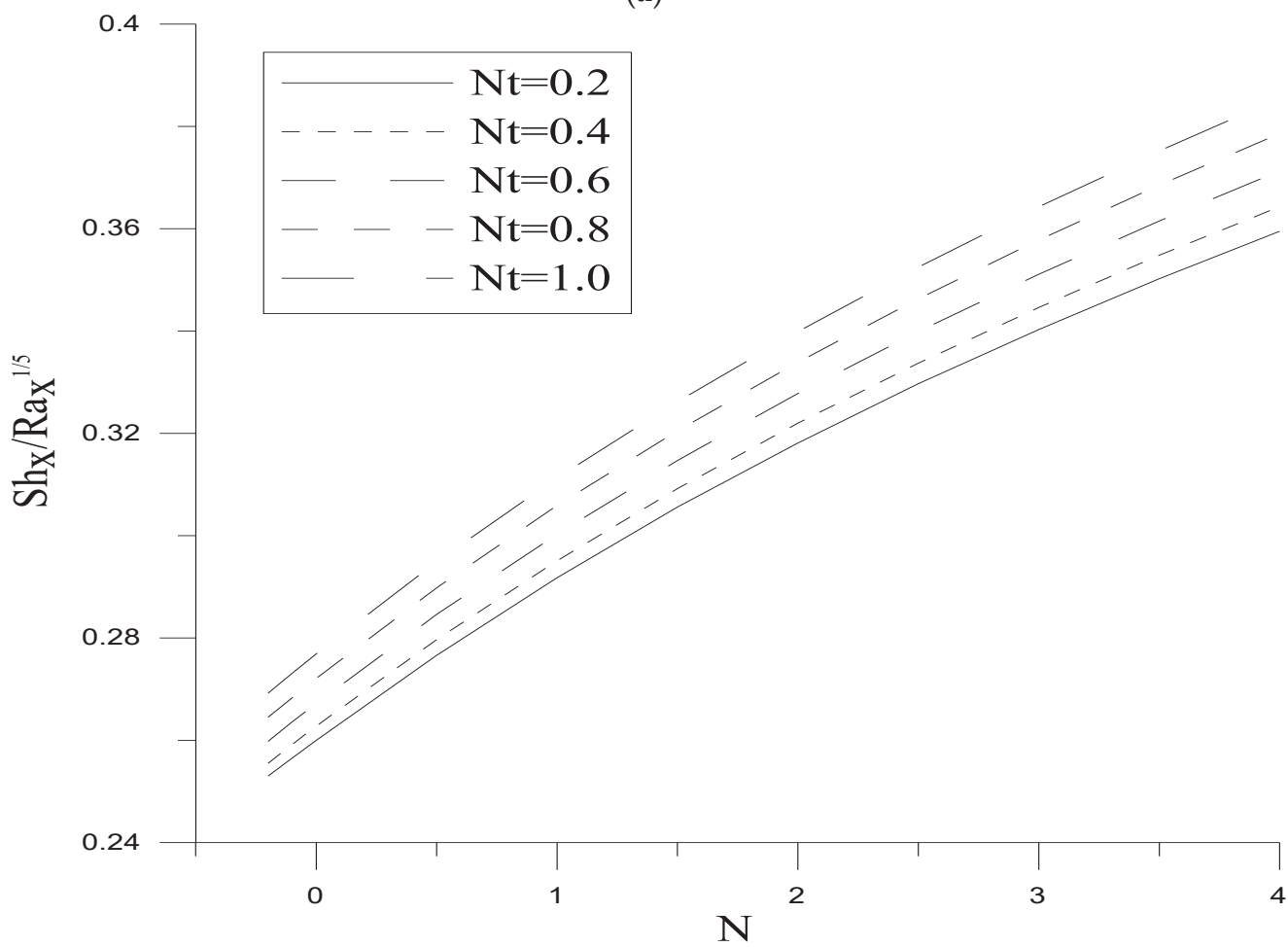

(b)

Figure 10. $(\mathbf{a}, \mathbf{b})$ Local Nusselt and Sherwood numbers with various values of $N t$ and $N$ at $\xi=1.0$, $n=1.0, S c=1.0, \gamma=2.01, \varepsilon=0.45, \kappa=0.5$, and $f_{w}=0.0$.

\section{Conclusions}

The thermophoretic effect on mass transfer characteristics over a vertical permeable surface with variable wall heat fluxes through a porous medium is analyzed. The nonDarcian effects that include inertia and boundary effects are considered. The mass transport 
mechanisms are coupled by diffusion, convection, thermophoresis, and suction/blowing effects. The special contribution of our investigation is discussing the phenomenon of thermophoresis related to low Schmidt number gas flow through a porous medium under a power-law exponent of wall heat flux conditions. The governing equations were transformed using similarity analysis, and the solutions were obtained using a numerical scheme. The results show the interactive effects of thermophoresis, suction/blowing, mass diffusivity, and buoyancy force on the mass transfer rates for low Schmidt number gases. To sum up, the concentration profiles decrease with increasing suction $\left(f_{w}\right)$, inertia $(\gamma)$, buoyancy ratio $(N)$, Schmidt number $(S c)$, and thermophoretic parameter $(N t)$; however, it increases with an increasing exponent $(n)$ and position parameter $(\xi)$. The results can realize the physical phenomena of gas diffusion through a porous medium and improve the transport mechanism.

Funding: This research was funded by Ministry of Science and Technology, Taiwan for support through grant number MOST 110-2222-E-033-004-.

Conflicts of Interest: The authors declare no conflict of interest.

\section{Nomenclature}

\begin{tabular}{|c|c|}
\hline$A$ & strength of wall heat source \\
\hline C & species concentration \\
\hline$C_{c}$ & Cunningham correction factor \\
\hline$C_{i}$ & Forcheimer inertia coefficient \\
\hline$C_{s} \quad C_{t} \quad C_{m}$ & constants in Equation (9) \\
\hline$D$ & mass diffusivity \\
\hline$d$ & pore diameter \\
\hline$f$ & dimensionless flow stream function \\
\hline$f_{w}$ & suction/blowing parameter \\
\hline$G, H, I$ & auxiliary functions \\
\hline$g$ & gravity \\
\hline$g_{m}$ & mass transfer conductance \\
\hline$J$ & mass flux \\
\hline K & Darcy permeability \\
\hline$K_{n}$ & Knudsen number \\
\hline$k$ & thermal conductivity \\
\hline$N$ & buoyancy ratio \\
\hline$N t$ & thermophoretic parameter \\
\hline$N u$ & Nusselt number \\
\hline$n$ & exponent of heat flux \\
\hline$P$ & pressure \\
\hline $\operatorname{Pr}$ & Prandtl number \\
\hline$q$ & heat flux \\
\hline$R a$ & Rayleigh number \\
\hline Sc & Schmidt number \\
\hline Sh & Sherwood number \\
\hline$T$ & temperature \\
\hline$T^{*}$ & characteristic temperature \\
\hline$(u, v)$ & streamwise and normal velocity components, respectively \\
\hline$V_{T}$ & thermophoretic velocity \\
\hline$(x, y)$ & streamwise and normal coordinates, respectively \\
\hline \multicolumn{2}{|c|}{ Greek symbols } \\
\hline$\alpha$ & thermal diffusivity \\
\hline$\beta_{T}$ & thermal expansion coefficient \\
\hline$\beta_{C}$ & concentration expansion coefficient \\
\hline$\gamma$ & inertia parameter \\
\hline$\Delta$ & due to difference \\
\hline
\end{tabular}




\begin{tabular}{ll}
\hline$\varepsilon$ & porosity \\
$\eta$ & similarity parameter \\
$\theta$ & dimensionless temperature \\
$\kappa$ & thermophoretic coefficient \\
$\lambda_{g}, \lambda_{p}$ & thermal conductivities of the fluid and particles, respectively \\
$\mu$ & fluid dynamic viscosity \\
$v$ & fluid kinematic viscosity \\
$\xi$ & dimensionless variable \\
$\rho$ & fluid density \\
$\phi$ & dimensionless concentration \\
$\psi$ & stream function \\
Subscripts and superscripts & \\
$\infty$ & ambient \\
$w$ & wall \\
$e$ & effective \\
\hline
\end{tabular}

\section{References}

1. Goldsmith, P.; May, F.G. Diffusiophoresis and thermophoresis in water vapor systems. In Aerosol Science; Davies, C.N., Ed.; Academic Press: London, UK, 1966; pp. 163-194.

2. Goren, S.L. Thermophoresis of aerosol particles in the laminar boundary layer on a flat surface. J. Colloid Interf. Sci. 1977, 61, 77-85. [CrossRef]

3. Homsy, G.M.; Geyling, F.T.; Walker, K.L. Blausius series for thermophoresis deposition of small particles. J. Colloid Interf. Sci. 1981, 83, 495-501. [CrossRef]

4. Hales, J.M.; Schwendiman, L.C.; Horst, T.W. Aerosol transport in a naturally convected boundary layer. Int. J. Heat Mass Transf. 1972, 15, 1837-1850. [CrossRef]

5. Mills, A.F.; Huang, X.; Ayazi, F. The effect of wall suction and thermophoresis on aerosol particle deposition from a laminar boundary layer on a flat plate. Int. J. Heat Mass Transf. 1984, 27, 1110-1113. [CrossRef]

6. Tsai, R. Aerosol particle transport in a natural convection flow onto a vertical flat plate. Int. J. Heat Mass Transf. 2001, 44, 867-870. [CrossRef]

7. Talbot, L.; Chenge, R.K.; Schefer, A.W.; Wills, D.R. Thermophoresis of particle in a heated boundary layer. J. Fluid Mech. 1980, 101, 737-758. [CrossRef]

8. Chamkha, A.J.; Pop, I. Effect of thermophoresis particle deposition in free convection boundary layer from a vertical flat plate embedded in a porous medium. Int. Commun. Heat Mass Transf. 2004, 31, 421-430.

9. Seddeek, M.A. Influence of viscous dissipation and thermophoresis on Darcy-Forchheimer mixed convection in a fluid saturated porous media. J. Colloid Interf. Sci. 2006, 293, 137-142. [CrossRef]

10. Seddeek, M.A.; Odda, S.N.; Abdelmeguid, M.S. Numerical study for the effects of thermophoresis and variable thermal conductivity on heat and mass transfer over an accelerating surface with heat source. Comput. Mater. Sci. 2009, 47, 93-98. [CrossRef]

11. Bejan, A.; Anderson, R. Heat transfer across a vertical impermeable partition embedded in porous medium. Int. J. Heat Mass Transf. 1981, 24, 1237-1245. [CrossRef]

12. Bejan, A.; Khair, K.R. Heat and mass transfer by natural convection in a porous medium. Int. J. Heat Mass Transf. 1985, 28, 909-918. [CrossRef]

13. Nakayama, A.; Koyama, H. An integral method for free convection from a vertical heated surface in a thermally stratified porous medium. Wärme-und Stoffübertragung 1987, 21, 297-300. [CrossRef]

14. Nakayama, A.; Koyama, H. Effect of thermal stratification on free convection within a porous medium. J. Thermophys. Heat Transf. 1987, 282-285. [CrossRef]

15. Epstein, M.; Hauser, G.M.; Henry, R.E. Thermophoretic deposition of particles in natural convection flow from vertical plate. ASME J. Heat Transf. 1985, 107, 272-276.

16. Garg, V.K.; Jayaraj, S. Thermophoresis of aerosol particles in laminar flow over inclined plates. Int. J. Heat Mass Transf. 1988, 31, 875-890. [CrossRef]

17. Jayaraj, S.; Dinesh, K.K.; Pillai, K.L. Thermophoresis in natural convection with variable properties. Heat Mass Transf. 1999, 34, 469-475. [CrossRef]

18. Zueco, J.; Beg, O.A.; Takhar, H.S.; Prasad, V.R. Thermophoretic hydromagnetic dissipative heat and mass transfer with lateral mass flux, heat source, Ohmic heating and thermal conductivity effects: Network simulation numerical study. Appl. Therm. Eng. 2009, 29, 2808-2815. [CrossRef]

19. Chamkha, A.J.; Jaradat, M.; Pop, I. Thermophoresis free convection from a vertical cylinder embedded in a porous medium. Int. J. Appl. Mech. Eng. 2004, 9, 471-481.

20. Nield, D.A.; Bejan, A. Convective in Porous Media, 2nd ed.; Springer: New York, NY, USA, 1999. 
21. Ingham, D.; Pop, I. (Eds.) Transport Phenomena in Porous Media I; Pergamon: Oxford, UK, 1998.

22. Ingham, D.; Pop, I. (Eds.) Transport Phenomena in Porous Media II; Pergamon: Oxford, UK, 2002.

23. Postelnicu, A. Effects of thermophoresis particle deposition in free convection boundary layer from a horizontal flat plate embedded in a porous medium. Int. J. Heat Mass Transf. 2007, 50, 2981-2985. [CrossRef]

24. Partha, M.K. Suction/injection effects on thermophoresis particle deposition in a non-Darcy porous medium under the influence of Soret, Dufour effects. Int. J. Heat Mass Transf. 2009, 52, 1971-1979. [CrossRef]

25. Tsai, R.; Huang, J.S. Combined effects of thermophoresis and electrophoresis on particle deposition onto a vertical flat plate from mixed convection flow through a porous medium. Chem. Eng. J. 2010, 157, 52-59. [CrossRef]

26. Postelnicu, A. Thermophoresis particle deposition in natural convection over inclined surfaces in porous media. Int. J. Heat Mass Transf. 2012, 52, 2087-2094. [CrossRef]

27. Koumy, E.S.R.; Barakat, E.S.I.; Abdelsalam, S.I. Hall and transverse magnetic field effects on peristaltic flow of a maxwell fluid through a porous medium. Glob. J. Pure Appl. Math. 2013, 9, 187-203.

28. Makinde, O.D.; Khan, W.A.; Culham, J.R. MHD variable viscosity reacting flow over a convectively heated plate in a porous medium with thermophoresis and radiative heat transfer. Int. J. Heat Mass Transf. 2016, 93, 595-604. [CrossRef]

29. Irfan, M.; Farooq, M.A. Thermophoretic MHD free stream flow with variable internal heat generation/absorption and variable liquid characteristics in a permeable medium over a radiative exponentially stretching sheet. J. Mater. Res. Technol. 2020, 9, 4855-4866. [CrossRef]

30. Rafique, K.; Anwar, M.I.; Misiran, M.; Khan, I.; El-Sayed, M.; Sherif, E.S.M. The Implicit Keller Box Scheme for Combined Heat and Mass Transfer of Brinkman-Type Micropolar Nanofluid with Brownian Motion and Thermophoretic Effect Over an Inclined Surface. Appl. Sci. 2020, 10, 280. [CrossRef]

31. Bird, R.B.; Stewart, W.E.; Lightfoot, E.N. Transport Phenomena; John Wiley and Sons: New York, NY, USA, 1992.

32. Batchelor, G.K.; Shen, C. Thermophoretic deposition in gas flow over cold surfaces. J. Colloid Interf. Sci. 1985, 107, 21-37. [CrossRef]

33. Ergun, S. Fluid flow through packed columns. Chem. Eng. Prog. 1952, 48, 89-94.

34. Elbashbeshy, E.M.A.; Bazid, M.A.A. The mixed convection along a vertical plate with variable surface heat flux embedded in porous medium. Appl. Math. Comput. 2002, 125, 317-324. [CrossRef]

35. Mills, A.F. Heat and Mass Transfer; Irwin: New York, NY, USA, 1995.

36. Minkowycz, W.J.; Sparrow, E.M. Numerical solution scheme for local nonsimilarity boundary-layer analysis. Numer. Heat Transf. 1978, 1, 69-85.

37. Rabadi, N.J.; Dweik, Y.J. Local non-similarity solutions for mixed convection flow with lateral mass flux over an inclined flat plate embedded in a Saturated Porous Medium. J. King Saud Univ. Eng. Sci. 1995, 7, 267-287. [CrossRef]

38. El-Amin, M.F. Combined effect of viscous dissipation and Joule heating on MHD forced convection over a non-isothermal horizontal cylinder embedded in a fluid saturated porous medium. J. Magn. Magn. Mater. 2003, 263, 337-343. [CrossRef]

39. Pal, D.; Mondal, H. Effects of Soret Dufour, chemical reaction and thermal radiation on MHD non-Darcy unsteady mixed convective heat and mass transfer over a stretching sheet. Commun. Nonlinear Sci. Numer. Simul. 2011, 16, $1942-1958$.

40. Pal, D.; Mondal, H. Influence of thermophoresis and Soret-Dufour on magnetohydrodynamic heat and mass transfer over a non-isothermal wedge with thermal radiation and Ohmic dissipation. J. Magn. Magn. Mater. 2013, 331, $250-255$. 